Fossil Energy Program

ANL/FE-91/2

Fossil Energy Program

Fossl Energy Program

Fossil Energy Program

Fossil Energy Program

Fossil Energy Program

Fossil Energy Program

Fossil Energy Program

Fossil Energy Program

Fossil Energy Program

Fossil Energy Program

Fossil Eriergy Program

Fossil Energy Program

Fossil Energy Program

Fossil Energy Program

Fossil Energy Program

Fossil Energy Program

Fossil Energy Program

Fossil Energy Frogram

Fossil Energy Program

Fossil Energy Proyram

Fossil Energy Program

Fossil Energy Program

Fossil Energy Program

Fossil Energy Program

Fossil Energy Program

Fossil Energy Program

Fossil Energy Frogram

Fossil Energy Program

Fossil Energy Program

Fossil Energy Program

Fossil Energy Program

Fossil Energy Program

Fossil Energy Program

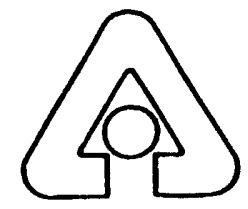

Argonne National Laboratory, Argonne, Illinois 60439

operated by The University of Chicago

for the United States Department of Energy under Contract W-31-109-Eng-38

Engineering Physics

Division

Engineering Physics

Division

Engineering Physics

Division

Engineering Physics

Division

\title{
Radiation Properties of Coal Combustion Products
}

by K. H. Im and R. K. Ahluwalia 
Argonne National Laboratory, with facilities in the states of Illinois and Idaho, is owned by the United States government, and operated by The University of Chicago under the provisions of a contract with the Department of Energy.

\section{DISCLAIMER}

This report was prepared as an account of work sponsored by an agency of the United States Government. Neither the United States Government nor any agency thereof, nor any of their employees, makes any warranty, express or implied, or assumes any legal liability or responsibility for the accuracy, completeness, or usefulness of any information, apparatus, product, or process disclosed, or represents that its use would not infringe privately owned rights. Reference herein to any specific commercial product, process, or service by trade name, trademark, manufacturer, or otherwise, does not necessarily constitute or imply its endorsement, recommendation. or favoring by the United States Government or any agency thereof. The views and opinions of authors expressed herein do not necessarily state or reflect those of the United States Government or any agency thereof.

Reproduced from the best available copy.

Available to DOE and DOE contractors from the Office of Scientific and Technical Information

P.O. Box 62

Oak Ridge, TN 37831

Prices available from (615) 576-8401, FTS 626-8401

Available to the public from the

National Technical Information Service

U.S. Department of Commerce

5285 Port Royal Road

Springfield, VA 22161 
Distribution Category: Advanced Combustion and Alternative

Fuels (UC-104)

ANL $/$ FE- $91 / 2$

$\mathrm{ANL} / \mathrm{FE}--91 / 2$

DE92 001603

\section{Argonne National Laboratory \\ 9700 South Cass Avenue \\ Argonne, Illinois 60439}

\section{RADIATION PROPERTIES OF COAL COMBUSTION PRODUCTS}

by

K. H. Im and R. K. Ahluwalia

Engineering Physics Division

November 1990

Work supported by the U. S. Department of Energy, Office of Fossil Energy, Advanced Combustion and Alternative Fuels Department, under Contract W- 31 - 109 - Eng- 38 . 


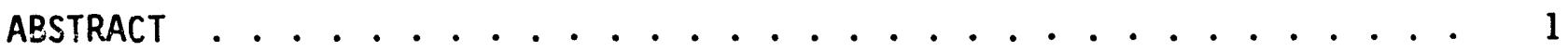

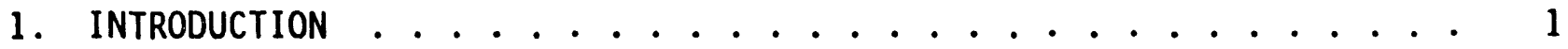

2. RADIATION PROPERTIES OF COMBUSTION GASES ........... 3

3. COAL OPTICAL CONSTANTS ..................... 4

4. CHAR OPTICAL CONSTANTS ................... 5

5. SOOT OPTICAL CONSTANTS ................ 7

6. ASH OPTICAL CONSTANTS ................. 10

7. ABSORPTION AND SCATTERING CROSS-SECTIONS . . . . . . . . . 24

8. DISCUSSION AND CONCLUSIONS ...................... 31

REFERENCES ..................... 36 


\section{LIST OF ILLUSTRATIONS}

Page

Figure 1. Dispersion Analysis of Char Extinction Data Obtained by

Brewster and Kunitomo (1984)............. . . 8

Figure 2. Char Optical Constants. . . . . . . . . . . . . . 9

Figure 3. Soot Optical Constants. . . . . . . . . . . . . . . 11

Figure 4. Optical Constants for Pittsburgh No. 8 Coal Ash Composition 18

Figure 5. Optical Constants for Illinois No. 6 Coal Ash Composition . . 19

Figure 6. Optical Constants for Eastern Coal Ash Composition. . . . . . 20

Figure 7. Comparison of Goodwin Correlation Against Data of Lowe et al. (1979) and Gupta and Wall (1985) . . . . . . . . . . . . 22

Figure 8. Comparison of Goodwin Correlation Against Data Presented in Blokh (1988). ...................... 23

Figure 9. Radiation Properties of Micronized Char Laden Combustion Gas . 27

Figure 10. Radiation Properties of Soot Laden Combustion Gas. . . . . . 29

Figure 11. Radiation Properties of Combustion Gas Laden with High-Iron Coal Ash Particulates. ................. 30

Figure 12. Radiation Properties of Combustion Gas Laden with Low-Iron Coal Ash Particulates. . . . . . . . . . . . . . 32

Figure 13. Radiation Properties of Combustion Gas Laden with Medium-Iron Coal Ash Particulates. . . . . . . . . . . . . . . 
Page

Table 1. Oscillator Parameters ............... 6

Table 2. Soot Dispersion Constants ............. 10

Table 3. Mixture Rule Parameters . . . . . . . . . . . 13

Table 4. Parameters Defining $g(\lambda) \ldots \ldots 14$

Table 5. Silica Absorption Index, $k_{0}(\lambda) \ldots \ldots 15$

Table 6. 0scillator Parameters for $8<\lambda<13 \mu \mathrm{m} \ldots \ldots 16$

Table 7. Oscillator Constants for $\mathrm{Al}_{2} \mathrm{O}_{3}$ and MgO Restrahlen Bands ... 17

Table 8. Ash Composition (\%) ............... 21

Table 9. Composition Dependence of Ash Optical Constants . . . . . 21

Table 10. Ash Composition of Australian and Russian Coals ...... 24 


\title{
RADIATION PROPERTIES OF COAL COMBUSTION PRODUCTS
}

by

K. H. Im and R. K. Ahluwalia

\begin{abstract}
An assessment is made of the experimental data and the theoretical bases for determining the absorption and scattering coefficients of the coal products of combustion. Particular attention is devoted to the complex refractive indices for char and ash. A dispersion relation is developed from sparse extinction data that can be used to estimate the optical constants of char. Considerable uncertainty and scatter is found in the literature data on ash optical constants and is attributed to variability in ash composition, lack of experimental rigor and limitations in the data reduction procedures. A correlation is presented for estimating the complex refractive indices of ash as a function of its mineral composition. A parametric study is conducted to elucidate the role of char, soot and ash particulates in determining the radiation properties of coal flames. The effects of combustion particulates are discussed in terms of the modification of the band structure of gas radiation to a luminous spectrum, introduction of scattering in radiation transport, particle size distribution, particle loading and particle composition. The results are interpreted as possible effects of coal beneficiation, coal micronization and flyash composition on heat transfer to the water walls of a coal furnace.
\end{abstract}

\section{INTRODUCTION}

The transfer of energy by infrared radiation from the flame to the waterwalls is a key process in utility steam generators using pulverized coal fuel. The major controlling factor in designing and operating a utility steam generator is the furnace exit temperature. This temperature determines whether ash deposits in the convection section will be molten and difficult to remove or 
flaky and easily controlled by soot blowing. Moreover, the need for attemperation of superheat steam and reheat steam has an impact on cycle efficiency and economics and is directly affected by the furnace exit temperature. This exit temperature is determined by the rate of fuel input, the burner design and by the radiative properties of the combustion gases and particulates. Thus, when utilities burn a coal different than that for which the furnace was designed, the unit must often be derated. Finally, the different radiative properties of the combustion products affect the furnace exit temperature and the heat transfer throughout the convective section.

It is generally agreed that the convective heat transfer is small compared to the transfer by radiation. The radiative transfer is due to both band emission from $\mathrm{CO}_{2}$ and $\mathrm{H}_{2} \mathrm{O}$ and continuous emission from the various types of particles which occur in the flame. Existing evidence indicates that particulate contribution is dominant and therefore plays a key role in determining furnace exit temperature. Since the radiation characteristics of the entrained particles can be expected to be related to coal type and particle size, changes in the radiative heat transfer are a possible cause of the observed sensitivity of furnace performance to the coal being fired.

The various types of particles entrained in the combustion gas can be classified as being carbonaceous (coal, char and soot) or noncarbonaceous/ inorganic (flyash). The carbonaceous particles are confined primarily to the firebox region whereas flyash may be the only type of particles remaining in the heat absorption region. The parameters determining particulate radiation are particle mass fraction and distribution in the flow field, particle size distribution, and the complex refractive index generally represented as $n+i k$ where $n$ and $k$ are, respectively, the refractive index and the absorption index. There is a considerable uncertainty in the literature data on complex refractive indices for coal combustion particulates. The uncertainties derive in part from the variabilities in particle composition, difficulties associated with the experimental techniques, and sometimes questionable methods employed in reducing the experimental data. One objective of this work is to present on a uniform basis the experimental data pertaining to combustion particulates, to assess the data base and to make recommendations on use of this data. A second objective is to present the absorption and scattering 
coefficients of coal combustion gas under typical furnace conditions and to quantify the role of combustion particulates in the radiative heat transfer process.

The use of micronized (mass mean diameter smaller than $10 \mu \mathrm{m}$ ) and deeply beneficiated (ash and sulfur contents less than 1\%) coal-based fuels being considered as a method of controlling pollution and displacing premium fuels. There is a need to assess how the furnace heat absorption pattern is impacted by finer-char and flyash size distributions, reduction in flyash particles loading and alteration of ash mineral content during coal beneficiation (e.g., pyrite is selectively removed in the physical cleaning step). Thus, the third objective of this work is to elaborate the effect of coal cleaning on the radiation properties of the combistion gas.

\section{RADIATION PROPERTIES OF COMBUSTION GASES}

In coal combustion, $\mathrm{CO}_{2}, \mathrm{H}_{2} \mathrm{O}$, and trace amounts of $\mathrm{CO}$ and $\mathrm{SO}_{2}$ are produced which participate in radiant heat transfer by the virtue of interaction of infrared radiation with vibrational and rotational modes of energy absorption by the gaseous molecules. The line structure of the vibration-rotation bands may be described by postulating a random spectrum of Lorentz lines of equal widths (Goody model). This postulate leads to the following definition of absorptivity of a homogeneous gas path of length $L$ for $i$ th species and $j$ th band (Ludwig et al. 1973).

$$
\alpha_{v i j}=1-\exp \left\{-(s / d)_{i j} p_{i} L\left[1+2(s / d)_{i j} p_{i} L /(2 \pi \gamma / d)_{i j}\right]^{-1 / 2}\right\}
$$

where $(s / d)_{1 j}$ is the ratio of mean intensity to line spacing, $p_{1}$ is density of absorber, and $(\gamma / d)_{i j}$ is the mean 1 ine width to spacing ratio. In a narrow band model, an extensive data base is developed on ( $s / d$ ), termed mean absorption coefficient, and the line density $1 / \mathrm{d}$ over the entire infrared spectrum for every vibration and rotation band of a gaseous species. An empirical correlation is constructed to determine the line width as a function of broadening pressures and gas temperatures. A comprehensive set of tabulations 
have been produced for the $1.14,1.38,1.87,2.7$ and $6.3 \mu \mathrm{m}$ bands of $\mathrm{H}_{2} \mathrm{O}, 1.9$, 2.7, 4.3 and $15 \mu \mathrm{m}$ bands of $\mathrm{CO}_{2}, 2.3$ and $4.7 \mu \mathrm{m}$ bands of $\mathrm{CO}$, and 4.0,4.3, $7.4,8.7$ and $19.3 \mu \mathrm{m}$ bands of $\mathrm{SO}_{2}$. Wide band models are constructed by prescribing a variation of $s / d$ and $\gamma / d$ versus $v$ within a band. In an exponential wide band model, $(\mathrm{s} / \mathrm{d})$ is assigned an exponential band shape. Regardless of the assumed band shape, compared to a narrow band model, the data base requirement is miniscule.

In radiation transport calculations, one needs to determine the absorption coefficient. It is intuitively possible to define an 'apparent' absorption coefficient of gas as

$$
K_{v}=\sum_{i} \sum_{j} \frac{-(s / d)_{i j} p_{i}}{1+\left[2(s / d)_{1 j} p_{i} L /(2 \pi \gamma / d)_{1 j}\right]^{1 / 2}}
$$

The optical beam length appears in the above definition of the gas absorption coefficient even though $x_{v}$ is a point property. The difficulty is a manifestation of the low resolution data base used in construction of the band models. In principle, true absorption coefficients can be determined from lineby-line calculations summing over the contributions of the isolated lines comprising gas bands (Clough, Kneizys and Chetwynd, 1977). A complementary high resolution spectroscopic data base is available for use at low temperatures (Rothman et al., 1987). The application of this data base to furnace temperatures, however, must await additional data on hot-band lines.

\section{COAL OPTICAL CONSTANTS}

In furnace heat transfer calculations, optical constants of coals are considered to be of secondary importance to char since the coal devolatilization time is generally insignificant compared to the char burnout time. Therefore, the literature on coal optical constants in the infrared range is mentioned here only briefly although it is quite extensive. Foster and Howarth (1968) employed a Fresnel reflectance technique to measure the complex refractive indices of coals of different ranks. Blokh (1982) presents a simi- 
lar compilation for Russian coals. Brewster and Kunitomo (1984) questioned the validity of the reflectance technique applied to coal. Using a transmission technique for small coal particles in $\mathrm{KBr}$, they measured absorption index of some Australian coals to be less than 0.05 in the infrared. These values are generally an order of magnitude smaller than the reflectance data. Solomon et al. (1986) and Grosshandler and Monteiro (1982) reported complementary data on spectral emissivities of coals of different ranks.

\section{CHAR OPTICAL CONSTANTS}

The literature on measurement of char optical properties is somewhat limited. Grosshandler and Monteiro (1982) measured efficiency factors for absorption (spectral absorptivity in the terminology of the authors) by char particles (differences between coal and char indiscernible) in the 1.2.5.3 $\mu \mathrm{m}$ spectral range. Solomon et al. (1986) employed FTIR spectrometry to measure spectral emissivity of char produced from Montana Rosebud coal. Neither set of data is appropriate for deriving fundamental information on complex refractive indices of char particles.

Brewster and Kunitomo (1984) extracted extinction efficiencies from transmissivity measurements on micron-sized char suspensions in a $\mathrm{KBr}$ pellet. The chars were prepared from three Australian coals ranging in nature from swelling (Saraji) to nonswelling (Sufco) coals. By using Mie theory and the dispersion equation for a free-electron oscillator, they deduced $n$ and $k$ which we found to be invalid and traced the discrepancy to some arithmetic errors in their numerical procedure. On request, Brewster (1990) supplied us the extinction efficiency data for reanalysis. An initial attempt to infer $n$ and $k$ by exploiting the substractive Kramer-Kronig ( $K-K)$ relationship together with Mie theory was unsuccessful. This method of correlation requires knowledge of a reference value of $\mathrm{n}$ at one wavelength. Conve:ged solutions could not be obtained for any choice of reference $n\left(\lambda_{0}\right)$. An alternative approach was adopted in which the $\mathrm{K}-\mathrm{K}$ relation was substituted with a generalized representation for combination of an arbitrary number of bound-electron oscillators and a free-electron oscillator. 


$$
\begin{aligned}
& n^{2}-k^{2}=n_{\infty}^{2}+\sum_{j} \frac{\omega_{p j}^{2}\left(\omega_{j}^{2}-\omega^{2}\right)}{\left(\omega_{j}^{2}-\omega^{2}\right)^{2}+\gamma_{j}^{2} \omega^{2}}-\frac{\omega_{f}^{2}}{\omega^{2}+\gamma_{f}^{2}} \\
& 2 n k=\sum_{j} \frac{\omega_{p j}^{2} \gamma_{j} \omega}{\left(\omega_{j}^{2}-\omega^{2}\right)^{2}+\gamma_{j}^{2} \omega^{2}}+\frac{\omega_{f}^{2} \gamma_{f}}{\omega\left(\omega^{2}+\gamma_{f}^{2}\right)}
\end{aligned}
$$

The oscillator parameters to be determined are $n_{\infty}$, the number of oscillators, plasma frequency $\omega_{p}$, resonant frequencies $\omega_{j}$ and $\omega_{f}$ and the damping frequencies $\gamma$ and $\gamma_{f}$. A nonlinear optimizer was used for this purpose such that spectral $n$ and $\mathbf{k}$ calculated from the dispersion relation yielded best leastsquare fit of the efficiency factor data. For consistency, the resonant frequencies were determined for one char and prescribed to be the same for other chars. Table 1 lists the oscillator parameters determined in this manner. The choice of the parameters should not be regarded as unique, and no physical significance can be attached to the location and strength of the oscillators. The efficiency data is not faithfully represented by a classical oscillator model in the sense that a choice of $n_{\infty}$ different than unity had to be made.

Table 1. Oscillator Parameters

\begin{tabular}{lccc}
\hline & Saraji Char & West Char & Sufco Char \\
\hline $\mathrm{r}_{\infty}$ & $2.046 \times 10^{-2}$ & $1.896 \times 10^{-2}$ & $3.012 \times 10^{-2}$ \\
$\omega_{\mathrm{f}}, \mathrm{cm}^{-1}$ & 1.371 & 1.286 & 0.916 \\
$\gamma_{\mathrm{f}} \mathrm{cm}^{-1}$ & $4.522 \times 10^{-4}$ & $1.548 \times 10^{-5}$ & $5.187 \times 10^{-3}$ \\
$\omega_{\mathrm{p} 1}, \mathrm{~cm}^{-1}$ & 3.55 & 3.542 & 2.252 \\
$\omega_{1}, \mathrm{~cm}^{-1}$ & 1.357 & 1.357 & 1.357 \\
$\gamma_{1}, \mathrm{~cm}^{-1}$ & 0.626 & 0.342 & 0.987 \\
$\omega_{\mathrm{p} 2}, \mathrm{~cm}^{-1}$ & 0.45 & 0.450 & 0.4 .51 \\
$\omega_{2}, \mathrm{~cm}^{-1}$ & 35.97 & 35.97 & 35.97 \\
$\gamma_{2}, \mathrm{~cm}^{-1}$ & 76.22 & 76.22 & 76.22 \\
$\omega_{\mathrm{p} 3}, \mathrm{~cm}^{-1}$ & 3.435 & 3.45 & 3.95 \\
$\omega_{3}, \mathrm{~cm}^{-1}$ & 0.759 & 0.759 & 0.759 \\
$\gamma_{3}, \mathrm{~cm}^{-1}$ & 2.166 & 1.964 & 3.896 \\
\hline
\end{tabular}


Figure 1 compares the measured extinction efficiency against the values calculated from Mie theory with complex refractive indices determined by the oscillator parameters given in Table 1 . The data are well represented at all interior points with noticeable disagreements at short and long wavelengths. The discrepancy at short wavelength is particularly disturbing isince a slight extrapolation into the visible region is necessary while calculating heat transfer. A fundamental concern is whether an extinction data base alone is sufficient for deriving optical constants. A need to distinguish between the absorption and scattering contributions to extinction for at least one data point seems obvious. It appears that a dispersion correlation might. be acceptable if it leads to extinction coefficients that maich the experimental data at all points. In that respect. the dispersion parameters for Saraji coal char appear most appropriate.

Figure 2 shows the spectral variations in optical constants of char determined from the oscillator parameters listed in Table 1. For comparison, the absorption index measurements of Hauser (1977) for an amorphous carbon film are also included. In general, there is a large discrepancy in magnitude and shape of the absorption index curves for char and amorphous carbon even though the two materials have some structural similarities. Further measurements of char optical constants are recommended to resolve the apparent discrepancy.

\section{SOOT OPTICAL CONSTANTS}

In coal combustion, soot production coincides with the stage of volatile matter being driven from the coal. There are no extant data on optical properties of coal soot, although voluminous data may be found on soot produced from other hydrocarbon fuels. Lee and Tien (1981) analyzed the optical constants of snot using the dispersion theory and determined some dispersion parameters rigorously and deduced the remaining unknowns from in-situ flame transmission data. Their dispersion constants for a two bound and one free electron oscillator model are summarized in Table 2. Their results indicate that the infrared optical properties of soot are relatively independent of the 


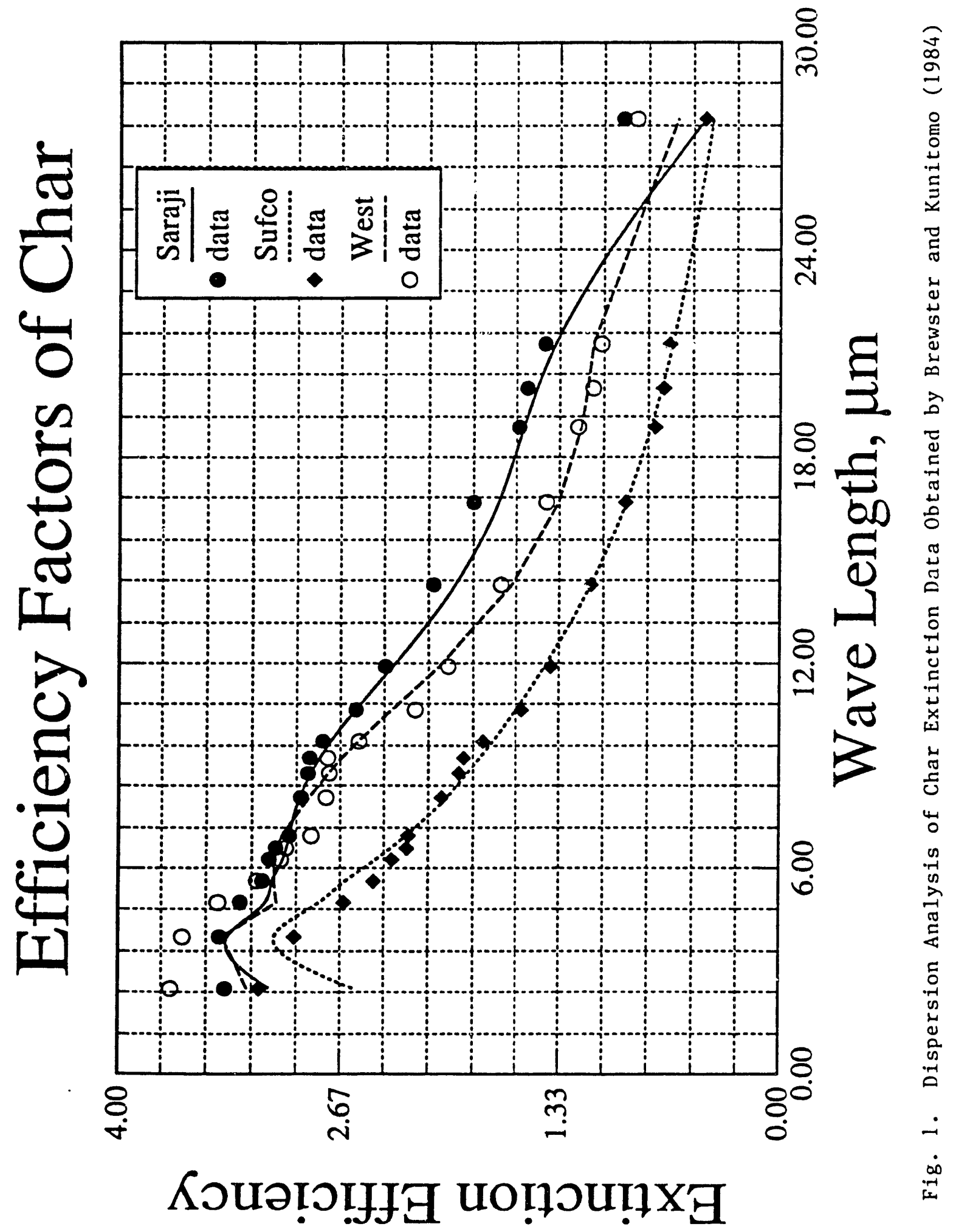




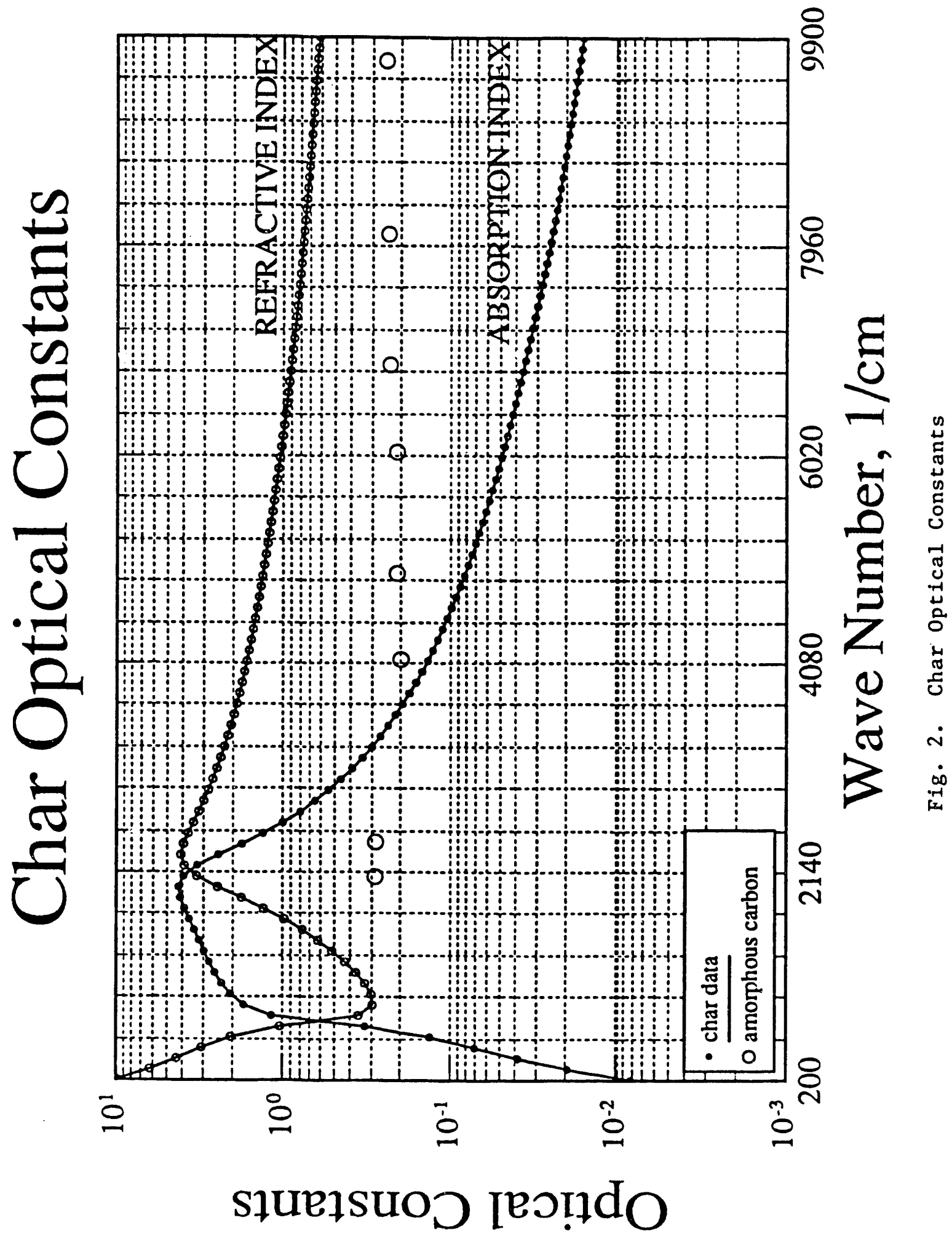


fuel hydrogen to carbon ratio and the molecular structure of soot. Thus the tabulated data can be regarded as some mean values applicable to many fuels. Finally, the absorption and refractive indices estimated from their correlations at $1500 \mathrm{~K}$ are presented in Fig. 3 .

Table 2. Soot Dispersion Constants

\begin{tabular}{lcc}
\hline & $1450 \mathrm{~K}$ & $300 \mathrm{~K}$ \\
\hline$n_{\infty}$ & 1 & 1 \\
$\omega_{\mathrm{f}}, \mathrm{cm}^{-1}$ & $5.049 \times 10^{4}$ & $5.049 \times 10^{4}$ \\
$\gamma_{\mathrm{f}}, \mathrm{cm}^{-1}$ & $4.0 \times 10^{4}$ & $1.819 \times 10^{4}$ \\
$\omega_{\mathrm{p} 1}, \mathrm{~cm}^{-1}$ & $1.201 \times 10^{5}$ & $1.201 \times 10^{5}$ \\
$\omega_{01}, \mathrm{~cm}^{-1}$ & $4.167 \times 10^{4}$ & $4.167 \times 10^{4}$ \\
$\gamma_{1}, \mathrm{~cm}^{-1}$ & $1.967 \times 10^{5}$ & $8.947 \times 10^{4}$ \\
$\omega_{\mathrm{p} 2}, \mathrm{~cm}^{-1}$ & $3.979 \times 10^{5}$ & $3.979 \times 10^{5}$ \\
$\omega_{02}, \mathrm{~cm}^{-1}$ & $2.417 \times 10^{5}$ & $2.417 \times 10^{5}$ \\
$\gamma_{2}, \mathrm{~cm}^{-1}$ & $1.867 \times 10^{5}$ & $8.492 \times 10^{4}$ \\
\hline
\end{tabular}

\section{ASH OPTICAL CONSTANTS}

The existing data base on optical constants of ash can be classified according to the measurement technique used in the experiments. Willis (1970) measured relative intensities of light scattered at different angles from ash particles dispersed in a flowing gas. The complex refractive indices were derived from Fresnel relations that are strictly valid for plane media rather than dispersed particles. The use of this data reduction technique has been criticized by Goodwin (1986) to the extent that the reported values are judged as meaningless. A single-particle scattering technique was used by Wyatt (1980) in which angular scattering was inferred by directing a laser beam onto levitated ash particles. Imaginary part of the complex refractive index, ranging in magnitude from 0 to 0.008 , was inferred by comparing the scattering pattern against Mie theory for different values of particle size and $k$.

Volz (1973) and Gupta and Wall (1985) have employed the KBr pellet trans mission technique in which the ash particles are dispersed in $\mathrm{KBr}$ powder, the 


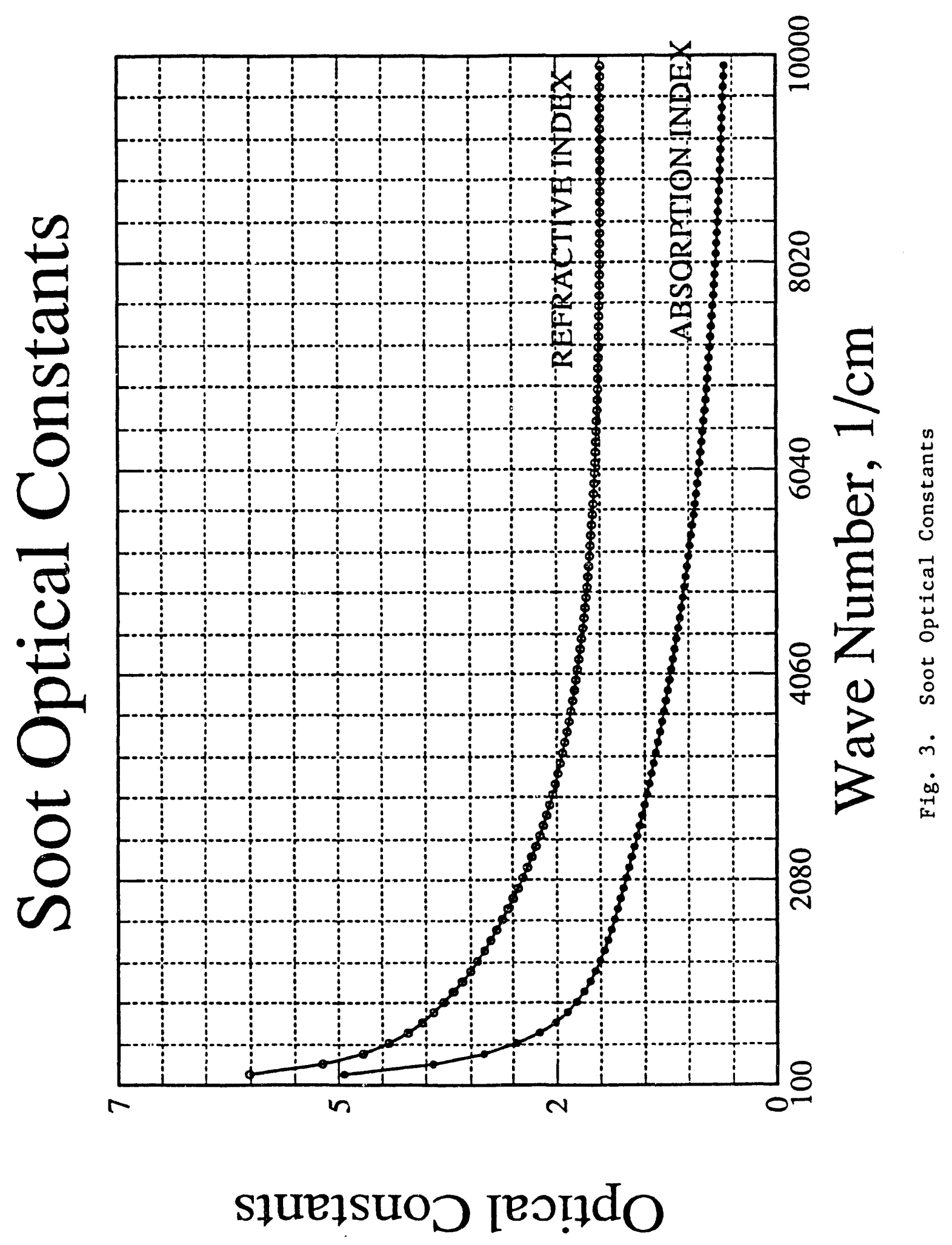


mixture compressed under vacuum in the shape of a disc, and the spectral transmittance measured through the disc. The imaginary part of the refractive index is inferred from transmittance by approximating the pellet as a homogeneous plane layer. Goodwin (1986) pointed out the limitations in the expression relating transmittance and $k$. The expression is strictly valid for a dilute suspension of particles with size parameter $2 \pi r / \lambda \ll 1$, i.e., negligible scattering in comparison to absorption, for $n$ near unity, and for $k$ much less than 1. One or more of these assumptions have been violated in the data reduction procedure.

Lowe et al. (1979) used a radiometric probe to measure emission at the exit of an Australian utility coal boiler. The measurements were made for several wavelengths in the windows of the gas bands. The absorption index was deduced from the measured emission spectra by assuming that emission was from ash alone. Gupta and Wall (1985) improved upon the radiometric technique and deduced $k$ that was a factor of two smaller than 0.01 to 0.02 values derived by Lowe et al. (1979). They also observed that the ash particles contained residual carbon and that the measurements were affected by the carbon content. The procedure used for reducing the emission data contained a number of simplifications whose accuracy is difficult to quantify.

Blokh (1988) reports extensive data on optical constants of ash particles from Russian coals. The data are apparently derived from extinction measurements on a flowing gas stream. Exact details on the experimental technique or the data reduction procedure are not available.

Goodwin (1986) performed systematic measurements of transmittance through, and, near-normal reflectance, on thin polished wafers cut from coal slags, from which the ash optical. constants were determined. The wafers were cut from synthetic slags, prepared from oxide powder mixtures, and natural slags. prepared by remelting flyash or gasifier slag. The transmittance spectra were measured at room temperature from 0.19 to $8 \mu \mathrm{m}$ and the reflectance spectra from 1 to $13 \mu \mathrm{m}$. The optical constants were determined from the transmittance and reflectance data at wavelengths where both sets of data were 
available. At wavelengths longer than $8 \mu \mathrm{m}$ the wafers were opaque, and a Kramers-Kronig analysis of the spectral reflectance data was made to compute the optical constants.

A mixture rule was developed to predict the real part of the refractive index from 1 to $8 \mu \mathrm{m}$ in terms of the mass fraction (Y) of the mineral constituents $\mathrm{SiO}_{2}, \mathrm{Al}_{2} \mathrm{O}_{3}, \mathrm{CaO}, \mathrm{MgO}$ and $\mathrm{Fe}_{2} \mathrm{O}_{3}$.

$$
n(\lambda)=\left[\frac{1+2 p \Sigma Y_{1} F_{i}(\lambda)}{1-p \Sigma Y_{1} F_{1}(\lambda)}\right]^{1 / 2}
$$

where

$$
\begin{aligned}
& p=2.54+0.00978 \mathrm{Y}_{\mathrm{PO}_{2} \mathrm{O},} \text { is the specific gravity and } \\
& F_{i}(\lambda)=\frac{a_{i} \lambda^{2}-b_{i}}{c_{1} \lambda^{2}-d_{1}} .
\end{aligned}
$$

Table 3 lists the parameters $a, b, c$ and $d$.

Table 3. Mixture Rule Parameters

\begin{tabular}{lllll}
\hline Oxide & \multicolumn{1}{c}{$a$} & \multicolumn{1}{c}{$b$} & \multicolumn{1}{c}{$c$} & \multicolumn{1}{c}{$d$} \\
\hline $\mathrm{SiO}_{2}$ & 0.9389 & 53.00 & 5.001 & 420.0 \\
$\mathrm{Al}_{2} \mathrm{O}_{3}$ & 1.914 & 174.0 & 10.36 & 1633.8 \\
$\mathrm{CaO}$ & 4.250 & 827.7 & 16.63 & 6102.3 \\
$\mathrm{Fe}_{2} \mathrm{O}_{3}$ & 1.647 & 0.00 & 11.36 & 0.00 \\
$\mathrm{TiO}_{2}$ & 2.720 & 260.0 & 15.80 & 1954.4 \\
$\mathrm{MgO}$ & 1.278 & 136.9 & 7.433 & 1200.9 \\
\hline
\end{tabular}

According to Goodwin's data, the imaginary part of the refractive index depends primarily on the iron, silica and $\mathrm{OH}$ contents of the slag. Iron is the primary absorber for $\lambda<4 \mu \mathrm{m}$. A correlation was developed for the effect of $\mathrm{Fe}$ in this wavelength region, accounting for both $\mathrm{Fe}^{2+}$ ligand-band absorption and $\mathrm{Fe}^{2+}-\mathrm{Fe}^{3+}$ intervalence charge transfer absorption. The cor- 
relation is given in terms of the molar concentrations of $\mathrm{Fe}^{2+}$ and $\mathrm{Fe}^{3+}$.

$$
\begin{aligned}
k(\lambda) & =A_{1} e^{1.75 / \lambda}+A_{2} g(\lambda) \\
A_{1} & =2.30 \times 10^{-5}\left[\mathrm{Fe}^{2+}\right]\left[\mathrm{Fe}^{3+}\right] \\
A_{2} & =7.685 \times 10^{-5}\left[\mathrm{Fe}^{2+}\right]+7.037 \times 10^{-6}\left[\mathrm{Fe}^{2+}\right]^{2} \\
{[\mathrm{Fe}] } & =\frac{2 P}{\mathrm{MW}_{\mathrm{Pe}_{2} \mathrm{O}_{3}}} \mathrm{Y}_{\mathrm{Fe}_{2} \mathrm{O}_{3}} \\
g(\lambda) & =\mathrm{a}_{1}\left(\lambda-\lambda_{u}\right)+\mathrm{b}_{1} \quad \lambda_{1}<\lambda<\lambda_{u}
\end{aligned}
$$

Table 4 provides the parameters comprising the $g(\lambda)$ expression.

Table 4. Parameters Defining $g(\lambda)$

\begin{tabular}{llcl}
\hline$\lambda_{l}$ & $\lambda_{u}$ & $\mathrm{a}_{1}$ & $\mathrm{~b}_{1}$ \\
\hline & 1.1 & 5.5 & 2.5 \\
1.1 & 1.54 & -1.3529 & 2.18 \\
1.54 & 1.9 & 0.7778 & 2.46 \\
1.9 & 2.3 & -0.9150 & 2.094 \\
2.3 & 2.6 & -0.6533 & 1.898 \\
2.6 & 4 & 0.1877 & 2.153 \\
\hline
\end{tabular}

In the longer wavelength region, $4<\lambda<8 \mu \mathrm{m}$, the absorption index is dominated by vibrational absorption due to Si-O-Si and Si-O-.

$$
\begin{aligned}
k(\lambda) & =\frac{\rho}{P_{0}} Y_{\mathrm{SiO}_{2}} k_{0}(\lambda) \\
P_{0} & =2.19, \text { specific gravity of fused silica. }
\end{aligned}
$$

Table 5 lists the spectral variation in $k_{0}(\lambda)$ at $T_{0}=300 \mathrm{~K}$. 
Table 5. Silica Absorption Index, $k_{0}(\lambda)$

\begin{tabular}{lllllll}
\hline$\lambda, \mu \mathrm{m}$ & \multicolumn{1}{c}{$\mathrm{k}_{0}, \mathrm{~m}^{-1}$} & $\lambda, \mu \mathrm{m}$ & $\mathrm{k}_{0}, \mathrm{~m}^{-1}$ & $\lambda, \mu \mathrm{m}$ & $\mathrm{k}_{0}, \mathrm{~m}^{-1}$ \\
\hline 4.00 & $5.79 \times 10^{-5}$ & 5.00 & $3.98 \times 10^{-3}$ & 6.667 & $7.16 \times 10^{-3}$ \\
4.082 & $7.99 \times 10^{-5}$ & 5.063 & $5.12 \times 10^{-3}$ & 6.897 & $8.51 \times 10^{-3}$ \\
4.167 & $1.07 \times 10^{-4}$ & 5.128 & $5.18 \times 10^{-3}$ & 7.143 & $1.06 \times 10^{-2}$ \\
4.255 & $1.32 \times 10^{-4}$ & 5.263 & $5.49 \times 10^{-3}$ & 7.407 & $1.48 \times 10^{-2}$ \\
4.348 & $2.13 \times 10^{-3}$ & 5.333 & $5.69 \times 10^{-3}$ & 7.692 & $3.72 \times 10^{-2}$ \\
4.396 & $2.65 \times 10^{-4}$ & 5.405 & $5.72 \times 10^{-3}$ & 7.752 & $4.74 \times 10^{-2}$ \\
4.444 & $2.84 \times 10^{-4}$ & 5.556 & $5.63 \times 10^{-3}$ & 7.813 & $7.68 \times 10^{-2}$ \\
4.494 & $2.84 \times 10^{-4}$ & 5.882 & $5.94 \times 10^{-3}$ & 7.874 & 0.132 \\
4.545 & $2.56 \times 10^{-4}$ & 6.061 & $6.32 \times 10^{-3}$ & 7.937 & 0.216 \\
4.651 & $2.62 \times 10^{-4}$ & 6.154 & $6.46 \times 10^{-3}$ & 8.00 & 0.323 \\
4.762 & $4.85 \times 10^{-4}$ & 6.250 & $6.52 \times 10^{-3}$ & & & \\
4.878 & $1.82 \times 10^{-3}$ & 6.452 & $6.57 \times 10^{-3}$ & & \\
\hline
\end{tabular}

In the intermediate wavelength region, the following temperature correction may be applied to the absorption index.

$$
k(T)=k\left(T_{0}\right)\left[1+\frac{2}{\exp (7194 / \lambda T)-1}\right]
$$

The optical constants in the wavelength range 8 to $13 \mu \mathrm{m}$ were observed to be dominated by three absorption bands. The first absorption peak at $9.4 \mu \mathrm{m}$ was attributed to Si-O vibration associated with bridging oxygen (i.e., Si-0$\mathrm{Si})$. The second peak at $10.4 \mu \mathrm{m}$ was observed to increase in strength with $\mathrm{Fe}_{2} \mathrm{O}_{3}$ content. This peak is associated with $\mathrm{Si}^{-0^{-}}$vibration (non-bridging oxygen). The third peak at approximately $13 \mu \mathrm{m}$ was similar to the peak seen in the fused silica spectrum, and may be due to the occurrence of ring groups. The experimental data were curve-fitted by a three-oscillator model with plasma frequencies expressed as a function of silica and iron mass fractions in ash. 


$$
\begin{aligned}
& n^{2}-k^{2}=n_{\infty}^{2}+\sum_{j=1}^{3} \frac{\omega_{p j}^{2}\left(\omega_{j}^{2}-\omega^{2}\right)}{\left(\omega_{j}^{2}-\omega^{2}\right)^{2}+\gamma_{j}^{2} \omega^{2}}, \quad n_{\infty}^{2}=2.15 \\
& 2 n k=\sum_{j=1}^{3} \frac{\omega_{p j}^{2} \gamma_{j} \omega}{\left(\omega_{j}^{2}-\omega^{2}\right)^{2}+\gamma_{j}^{2} \omega^{2}} \\
& \left(\frac{w_{p_{1}}}{w_{1}}\right)^{2}=\left(0.425-0.60 \mathrm{Y}_{\left.\mathrm{Fe}_{2} \mathrm{O}_{1}\right)}\right)\left(\frac{\mathrm{Y}_{\mathrm{S}_{1} \mathrm{O}_{2}}}{0.52}\right) \\
& \left(\frac{\omega_{p_{2}}}{\omega_{2}}\right)^{2}=\left(0.175+0.75 Y_{F_{2} O_{1}}\right)\left(\frac{Y_{S_{1} O_{2}}}{0.52}\right) \\
& \left(\frac{w_{p_{3}}}{w_{3}}\right)^{2}=0.053\left(\frac{Y_{S_{1} O_{2}}}{0.52}\right)
\end{aligned}
$$

Table 6 lists the resonant frequencies and the damping constants.

\begin{tabular}{lrrr} 
Table 6. & Oscillator Parameters & for $8<\lambda<13 \mu \mathrm{m}$ \\
\hline Oscillator & 1 & 2 & \multicolumn{1}{c}{3} \\
\hline$\omega_{j}, \mathrm{~cm}^{-1}$ & 1062.8 & 955.8 & 702.8 \\
$\gamma_{j}, \mathrm{~cm}^{-1}$ & 164.7 & 79.1 & 27.5 \\
\hline
\end{tabular}

No experimental data are reported for the long wavelength region $\lambda>$ $13 \mu \mathrm{m}$. At the suggestion of Goodwin, the optical constants in this range are assumed to be dominated by the Restrahlen bands of $\mathrm{Al}_{2} \mathrm{O}_{3}$ and $\mathrm{MgO}$. A fouroscillator $f(t)$ is used to describe the $\mathrm{Al}_{2} \mathrm{O}_{3}$ spectrum and a two-oscillator fit for MgO Restrahlen band. Table 7 summarizes the oscillator parameters for $\mathrm{Al}_{2} \mathrm{O}_{3}$ and $\mathrm{MgO}$ bands. In lieu of any better information, we adopt a simple mixture rule in which $\mathrm{n}$ and $\mathrm{k}$ for $\mathrm{Al}_{2} \mathrm{O}_{3}$ and $\mathrm{MgO}$ bands are mass-fraction averaged to obtain the optical constants for ash in the long wavelength region. 
Table 7. Oscillator Constants for $\mathrm{Al}_{2} \mathrm{O}_{3}$ and $\mathrm{MgO}$ Restrahlen Bands

\begin{tabular}{lclll}
\hline Oscillator & 1 & \multicolumn{1}{c}{2} & \multicolumn{1}{c}{3} & \multicolumn{1}{c}{4} \\
\hline a) $\mathrm{Al}_{2} \mathrm{O}_{3}, \mathrm{n}_{\infty}^{2}=3.01$ & & & \\
$\omega_{\text {oj }}, \mathrm{cm}^{-1}$ & 210.9 & 726.3 & 639.1 & 347.8 \\
$\omega_{j}, \mathrm{~cm}^{-1}$ & 383 & 442 & 369 & 635 \\
$\dot{\gamma}_{j}, \mathrm{~cm}^{-1}$ & 0.015 & 0.01 & 0.02 & 0.02 \\
b) $\mathrm{MgO}, \mathrm{n}_{\infty}^{2}=3.01$ & 1030.2 & 135.8 & & \\
$\omega_{\rho j}, \mathrm{~cm}^{-1}$ & 401 & 640 & & \\
$\omega_{j}, \mathrm{~cm}^{-1}$ & 7.62 & 102.6 & & \\
$\gamma_{j}, \mathrm{~cm}^{-1}$ & & & \\
\hline
\end{tabular}

The above correlations have been used to study the influence of mineral composition on optical constants of ash. Table 8 lists the mineral composition in three coals selected because of different iron contents. Pittsburgh No. 8 coal ash represents a high-iron ash, Illinois No. 6 coal ash an intermediate-iron ash, and Eastern coal ash a low-iron ash. The optical constants calculated for the three ashes are displayed in Figs. 4, 5 and 6 . As indicated in Table 9, four spectral regions may be identified. In the long wavelength region, $\lambda>13 \mu \mathrm{m}$, the optical constants are determined by the Restrahlen bands of alumina and magnesia. In this region, sharp peaks in absorption index are evident as are bands with refractive index much smaller than unity. The magnitudes of $\mathrm{n}$ and $\mathrm{k}$ are proportional to the $\mathrm{Al}_{2} \mathrm{O}_{3}$ and $\mathrm{MgO}$ contents, and thus are highest for Eastern coal ash. In the long intermediate wavelength region, $8<\lambda<13 \mu \mathrm{m}$, the complex refractive indices are determined by the Restrahlen bands of silica. Here, the width of the absorption band is proportional to the silica content of ash. In the short intermediate wavelength region, $4<\lambda<8 \mu \mathrm{m}, \mathrm{n}$ is given by the mixture rule and $\mathrm{k}$ by the absorption bands of silica glass. Both silica and iron constituents in ash contribute to absorption in this region. Pittsburgh No. 8 and Illinois No. 6 spectra exhibit an absorption peak at approximately $4.2 \mu \mathrm{m}$ which is indistinguishable in Eastern coal ash spectra because of its low iron content. Finally, in the short wavelength region, $\lambda<4 \mu \mathrm{m}$, the absorption is entirely due to $\mathrm{Fe}^{2+}$ ligand band and $\mathrm{Fe}^{2+}-\mathrm{Fe}^{3+}$ intervalence charge transfer. Thus, the magnitude of absorption index is directly proportional to the iron 


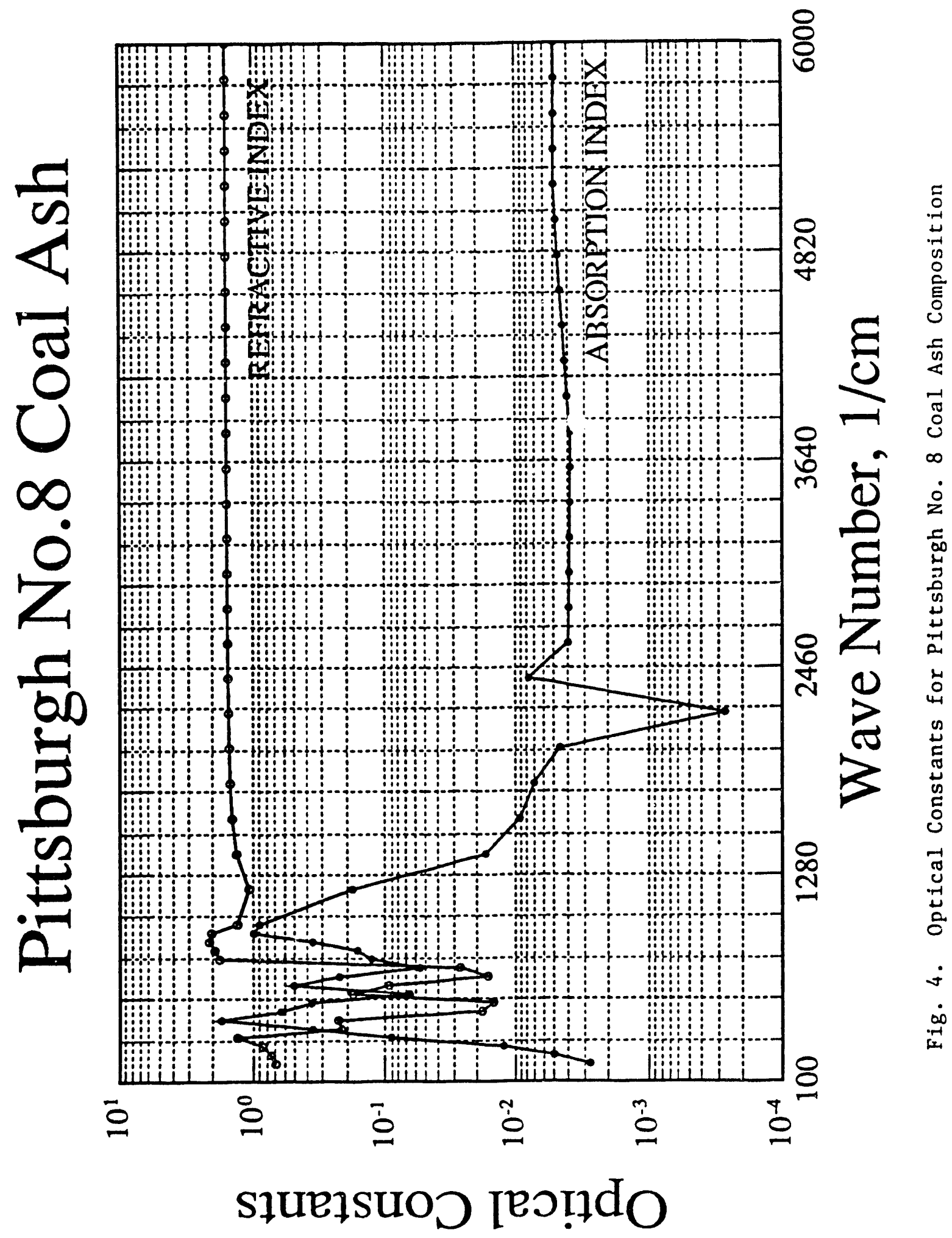




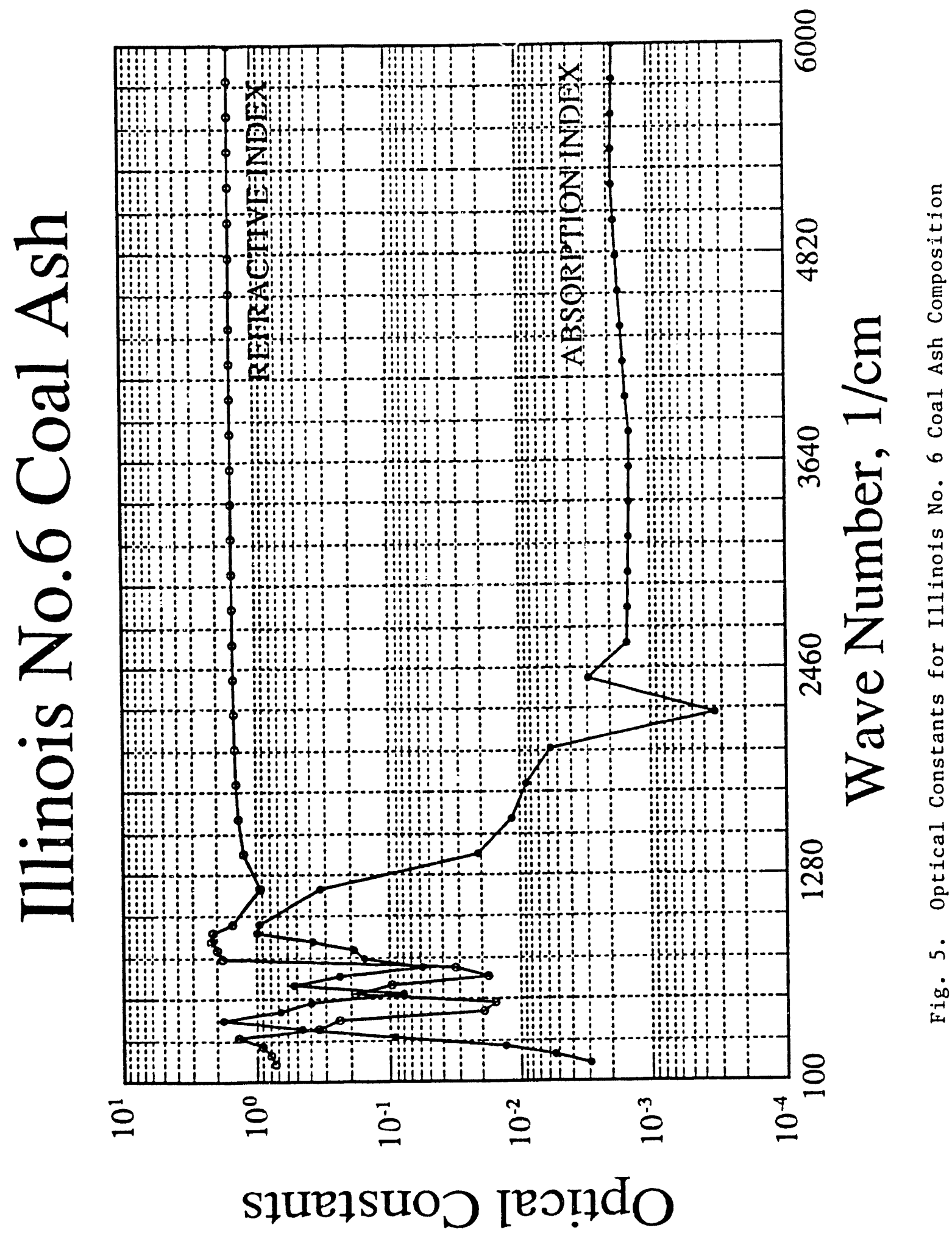




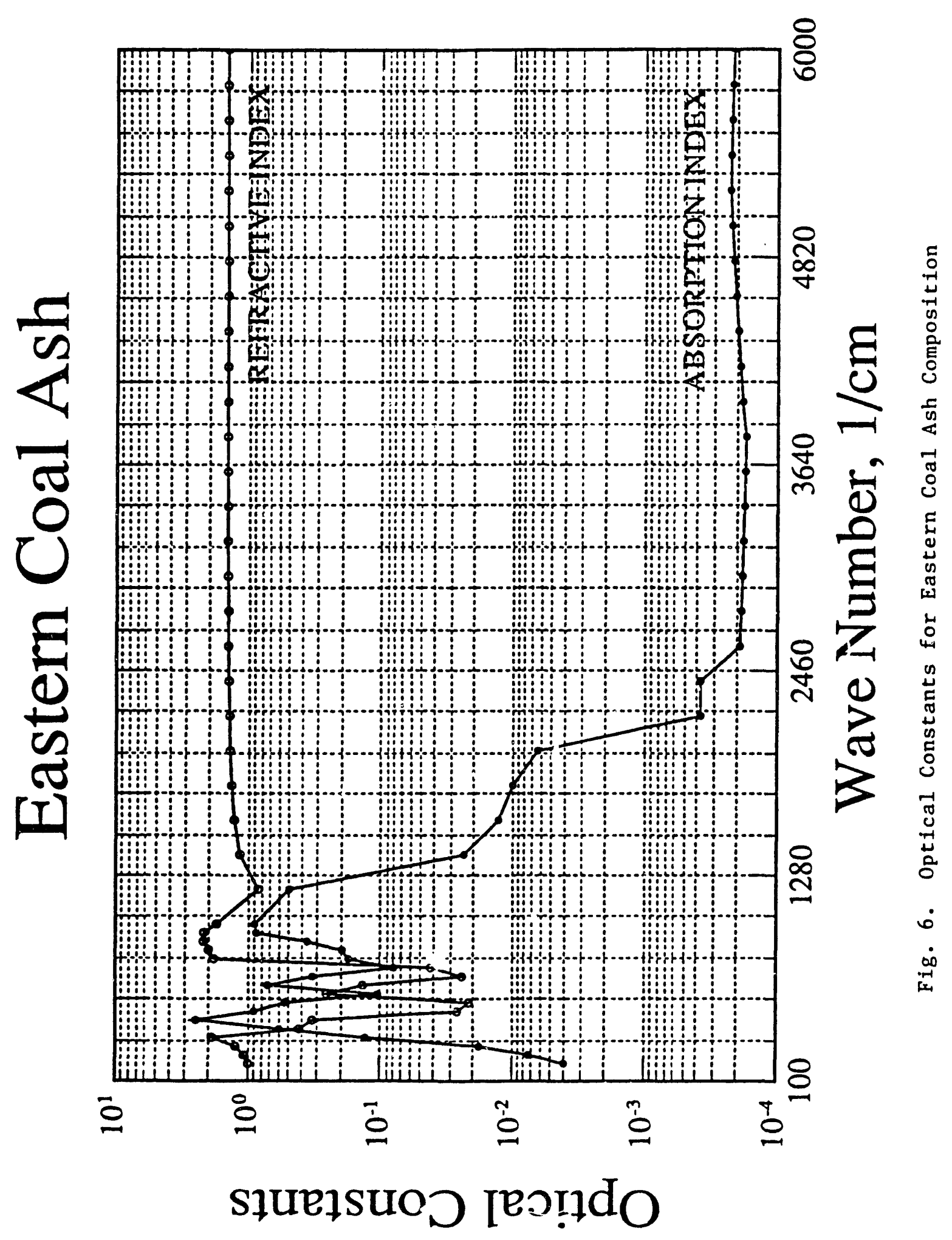


Table 8. Ash Composition ( $)$

\begin{tabular}{lccc}
\hline & $\begin{array}{c}\text { Pittsburgh } \\
\text { No. } 8\end{array}$ & $\begin{array}{c}\text { Illinois } \\
\text { No. } 6\end{array}$ & $\begin{array}{c}\text { Eastern } \\
\text { Coal }\end{array}$ \\
\hline $\mathrm{SiO}_{2}$ & 39.3 & 51.7 & 60.73 \\
$\mathrm{Al}_{2} \mathrm{O}_{3}$ & 20.2 & 20.7 & 28.90 \\
$\mathrm{CaO}$ & 3.0 & 2.2 & 0.71 \\
$\mathrm{Fe}_{2} \mathrm{O}_{3}$ & 31.4 & 16.9 & 3.33 \\
$\mathrm{MgO}$ & 0.8 & 0.9 & 0.83 \\
\hline
\end{tabular}

Table 9. Composition Dependence of Ash Optical Constants

\begin{tabular}{ccll}
\hline Wavelength & Wavenumber & Refractive Index, $\mathrm{n}$ & Absorption Index, $\mathrm{k}$ \\
\hline $1-4 \mu \mathrm{m}$ & $2500-10,000 \mathrm{~cm}^{-1}$ & $\begin{array}{l}\text { Mixture Rule for } \mathrm{SiO}_{2}, \\
\mathrm{CaO}, \mathrm{Fe}_{2} \mathrm{O}_{3} \text { and } \mathrm{MgO}\end{array}$ & $\mathrm{f}\left(\mathrm{Fe}^{++}, \mathrm{Fe}^{+++}\right)$ \\
$4-8 \mu \mathrm{m}$ & $1250-2500 \mathrm{~cm}^{-1}$ & $\begin{array}{l}\text { Mixture Rule for } \mathrm{SiO}_{2}, \\
\mathrm{CaO}, \mathrm{Fe}_{2} \mathrm{O}_{3} \text { and } \mathrm{MgO}\end{array}$ & Silica Glass Data \\
$8-13 \mu \mathrm{m}$ & $770-1250 \mathrm{~cm}^{-1}$ & $\begin{array}{l}\mathrm{SiO} \mathrm{O}_{2} \text { Restrahlen Band } \\
\mathrm{Al} \mathrm{O}_{3} \text { and MgO } \\
\text { Restrahlen Bands }\end{array}$ & $\begin{array}{l}\mathrm{SiO}_{2} \text { Restrahlen Band } \\
\mathrm{Al}_{2} \mathrm{O}_{3} \text { and MgO } \\
\text { Restrahlen Bands }\end{array}$ \\
\hline $13 \mu \mathrm{m}$ & $200-770 \mathrm{~cm}^{-1}$ &
\end{tabular}

content. The high frequency region is important in infrared radiation transfer since at temperatures typical of furnace operation, the peak in black body emissivity lies in this region. Thus all other things (ash content, particle size distribution) being equal, one would expect a greater enhancement in radiative heat transfer due to Pittsburgh No. 8 coal flyash than flyash liberated from Eastern coal.

Figures 7 and 8 represent an attempt to present ash optical data from different sources on a uniform basis. The optical constants for Australian coals (see Table 10 for ash composition) as measured by Lowe et al. (1979) and Gupta and Wall (1985) are compiled in Fig. 7 and compared with the Goodwin correlation usirg the coal ash composition with the highest iron content. The absorption indices measured in-situ and in the laboratory are one-to-two orders of magnitude larger than the values indicated by the correlation. The in-situ measurements are corrupted by residual carbon content (up to $10 \%$ carbon in ash) and contain inherent uncercaincles assocfated with obtaining and 


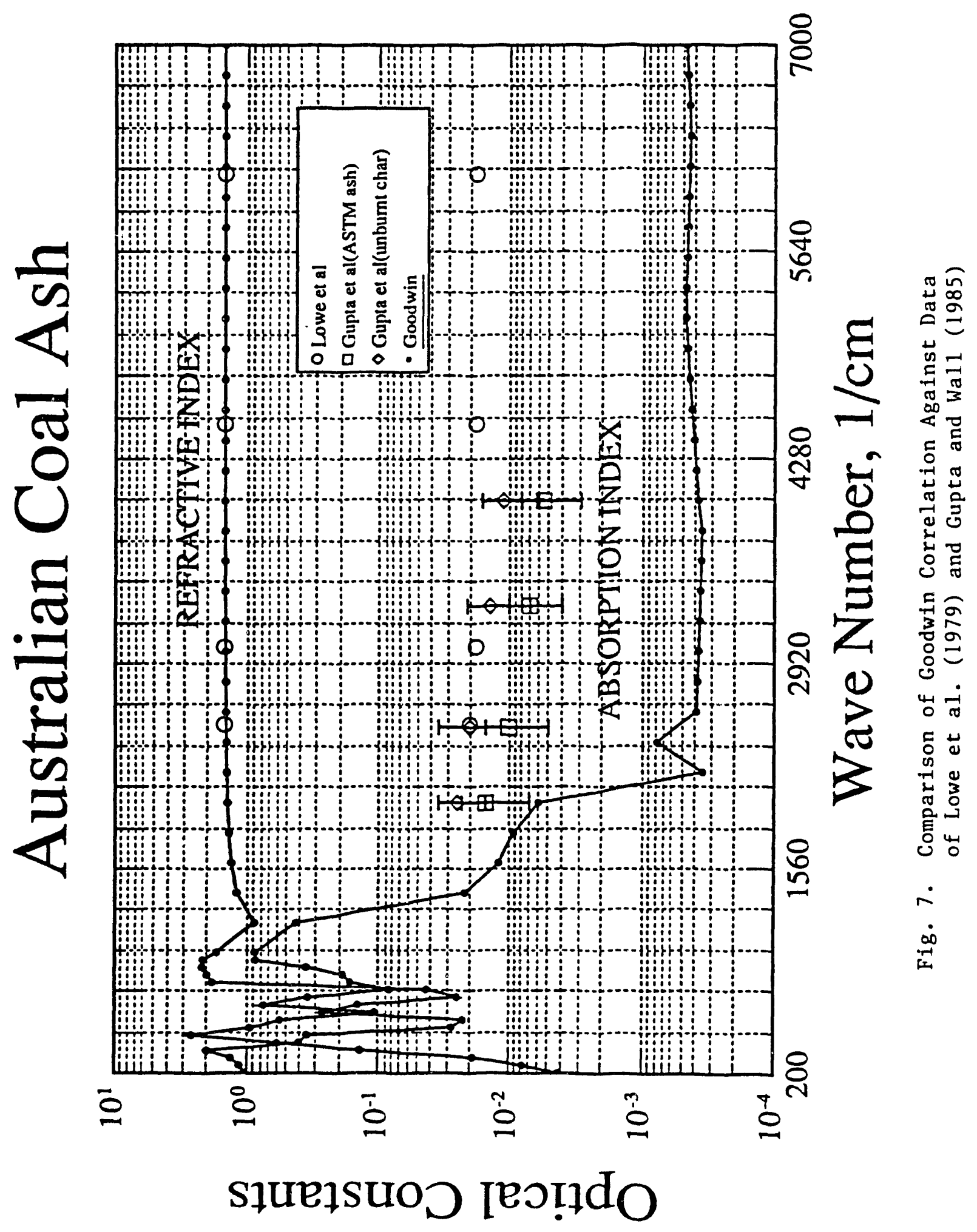




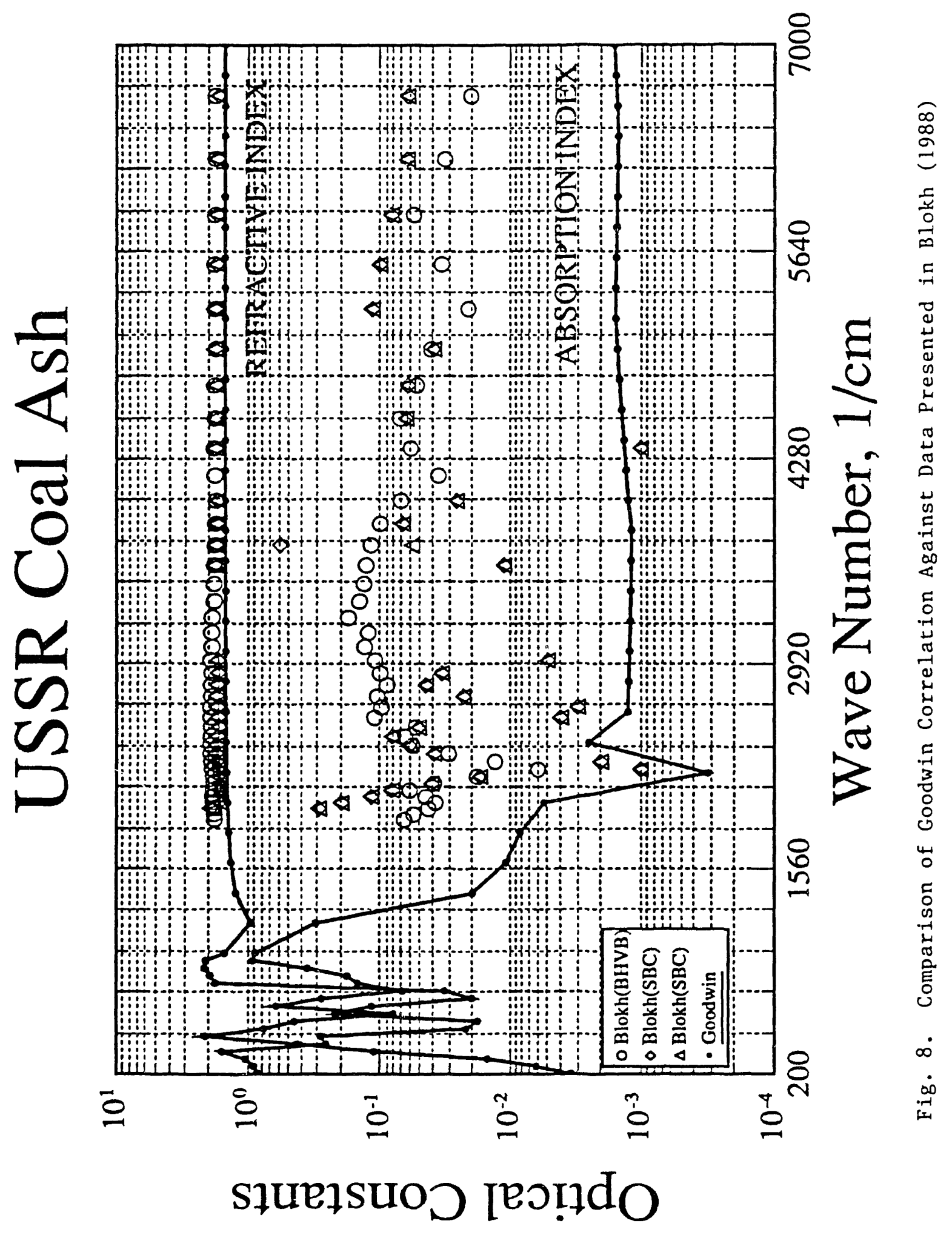


reducing data in an operational utility furnace. The laboratory measurements were conducted on carbon-free ASTM ash and represent an upper bound on the abscration Index since the likelihood of scattering was ignored during data reduction. Figure 8 depicts an equally dismal comparison between the Goodwin correlation applied to SBC coal ash composition and optica constants reported by Blokh (1988). The Russian data, however, is difficult to assess since few details are available on the experimental technique and the data reduction methodology.

Table 10. Ash Composition of Australian and Russian Coals

\begin{tabular}{lcccccc}
\hline & Luddell & Buchanan & Wangi & $\mathrm{Br}-1(\mathrm{SBC})$ & $\mathrm{Br}-2(\mathrm{SBC})$ & $\mathrm{B} 1-5(\mathrm{BHVB})$ \\
\hline $\mathrm{Al}_{2} \mathrm{O}_{3}$ & 30.25 & 18.51 & 29.43 & 11 & 13 & 25 \\
$\mathrm{CaO}$ & 1.29 & 0.52 & 0.69 & 42 & 26 & 5.5 \\
$\mathrm{Fe}_{2} \mathrm{O}_{3}$ & 6.89 & 2.35 & 4.07 & 9 & 8 & 15 \\
$\mathrm{~K}_{2} \mathrm{O}$ & 0.79 & 0.57 & 1.22 & & & \\
$\mathrm{MgO}$ & 0.90 & 0.37 & 0.42 & & 47 & 49 \\
$\mathrm{SiO}_{2}$ & 57.09 & 76.06 & 62.16 & 30 & & \\
$\mathrm{TiO}_{2}$ & 1.26 & 0.79 & 1.15 & & & \\
Other 0xides & 1.53 & 0.83 & 0.86 & & & \\
Residual Carbon & 7.0 & 10.1 & 3.5 & & & \\
\hline
\end{tabular}

\section{ABSORPTION AND SCATTERING CROSS-SECTIONS}

A number of parametric calculations have been performed to provide the expected magnitudes of absorption and scattering coefficients in coal combustion flames in a manner that facilitates understanding of the relative contributions of different participants. For the purpose of these benchmark calculations, the reference gas pressure and temperature are taken as $1500 \mathrm{~K}$ and one atmosphere, respectively. The mole fractions of $\mathrm{CO}_{2}$ and $\mathrm{H}_{2} \mathrm{O}$ are fixed at 0.14 and 0.08 . These are representative of coal $(6.2 \%$ moisture, $60 \%$ fixed carbon, $20 \%$ volatile matter) combusted in $10 \%$ excess air having $10 \%$ relative humidity. Under these conditions, the fuel-air ratio is 0.07 . 
Two types of char particle size distributions (psd) are considered. One is classified as pulverized char, produced from pulverized coal, represented by a log-normal psd with $50 \mu$ mass-median diameter (mmd) and 2.0 geometric standard deviation $\left(\sigma_{\mathrm{s}}\right)$. The second is classified as micronized char, produced from micronized coal, also represented by a log-normal psd but with 10 $\mu \mathrm{m}$ mmd and $2.0 \quad \sigma_{\mathrm{s}}$.

Two types of ash psd are considered. One is referred to as pulverizedcoal ash and represented by a log-normal psd with $7.5 \mu \mathrm{m}$ md and $2.0 \sigma_{\mathrm{s}}$. The pulverized coal from which the ash is liberated is assumed to contain $10 \%$ ash. The second type of ash is referenced as clean-coal ash. It is also assigned a log-normal psd but with $3.5 \mu \mathrm{mm}$ and $2.0 \sigma_{\mathrm{s}}$. The smaller particle size reflects an assumed fine grinding step in the process of cleaning coal down to 1\% ash level. For consistency in comparison, the mineral composition of ash is presumed to remain unchanged in the coal cleaning operations.

The effect of mineral composition is studied by considering a high silica/low iron ash (Eastern coal type ash), an intermediate silica/ intermediate iron ash (Illinois No. 6 coal type ash), and a low silica/high iron ash (Pittsburgh No. 8 coal type ash).

The size of primary soot particles generated in different fuel flames is generally much smaller than $0.10 \mu \mathrm{m}$. Soot particles have a noticeable tendency to form chain-like agglomerates. The amount of soot produced is a function of carbon to hydrogen ratio in fuel, combustion stoichiometry and the degree of fuel-air mixing in flame zone. In coal combustion, soot production is likely to be related to the volatile matter content, and both soot production and burnout are relatively unknown. We parametrize soot psd by a lognormal function with $0.05 \mu \mathrm{m}$ md and $2.0 \sigma_{\mathrm{s}}$, and by assuming that 0.05 to $1 \%$ volatile matter completes combustion via soot formation and burnout.

We propose using Mie theory for calculating the absorption and scattering cross-sections of combustion particulates. In applying Mie theory, the particles are regarded as spherical and compositionally uniform. Neither of these assumptions can be defended on the basis of physical appearance of char, 
soot or ash particles. Although questionable for single particles, the assumptions are not extreme when treating a cloud of particles with statistical variations in size, shape and composition. The averaging assumption has also been verified in some electromagnetic transport theories applied to a cloud of irregularly shaped particles.

The particle size distribution effects are resolved by adopting a histogram representation and using up to forty size bins. The efficiency factors are calculated for each size, weighted over cross-sectional area, and integrated over psd to obtain macroscopic absorption and scattering cross-sections.

We advocate spectral calculations of radiation properties since there exist no established rules by which spectral averaging can be carried out for combustion particles. For this purpose, the infrared radiation spectrum is discretized into thirty-seven frequency bands. The band centers are located to accommodate more than one frequency band per gas band. Each frequency band is further subdivided in twenty channels. The macroscopic absorption and scattering cross-sections for gaseous species and combustion particles are first calculated for twenty channels and then integrated to yield the average cross-sections for the constituent frequency band. The averaging procedure recognizes and attempts to account for the periodic nature of the particle efficiency factors with respect to the size parameter $2 \pi r / \lambda$, particle size distribution and the different types of particles having different frequencydependent optical constants. In this manner, 740 frequency calculations are required to capture the full spectral nature of radiation properties.

Figure 9 compares the macroscopic gas absorption cross-section to combined gas and micronized char absorption and scattering cross-sections. The char particle concentration has been multiplied by a factor of one-third to reflect the changes in char concentration with burnout. In Fig. 9, the gas absorption cross-section displays a band structure typical of gas radiation. Introduction of char particles modifies the spectral absorption cross-section from band structure to luminous radiation. The radiation windows between the 


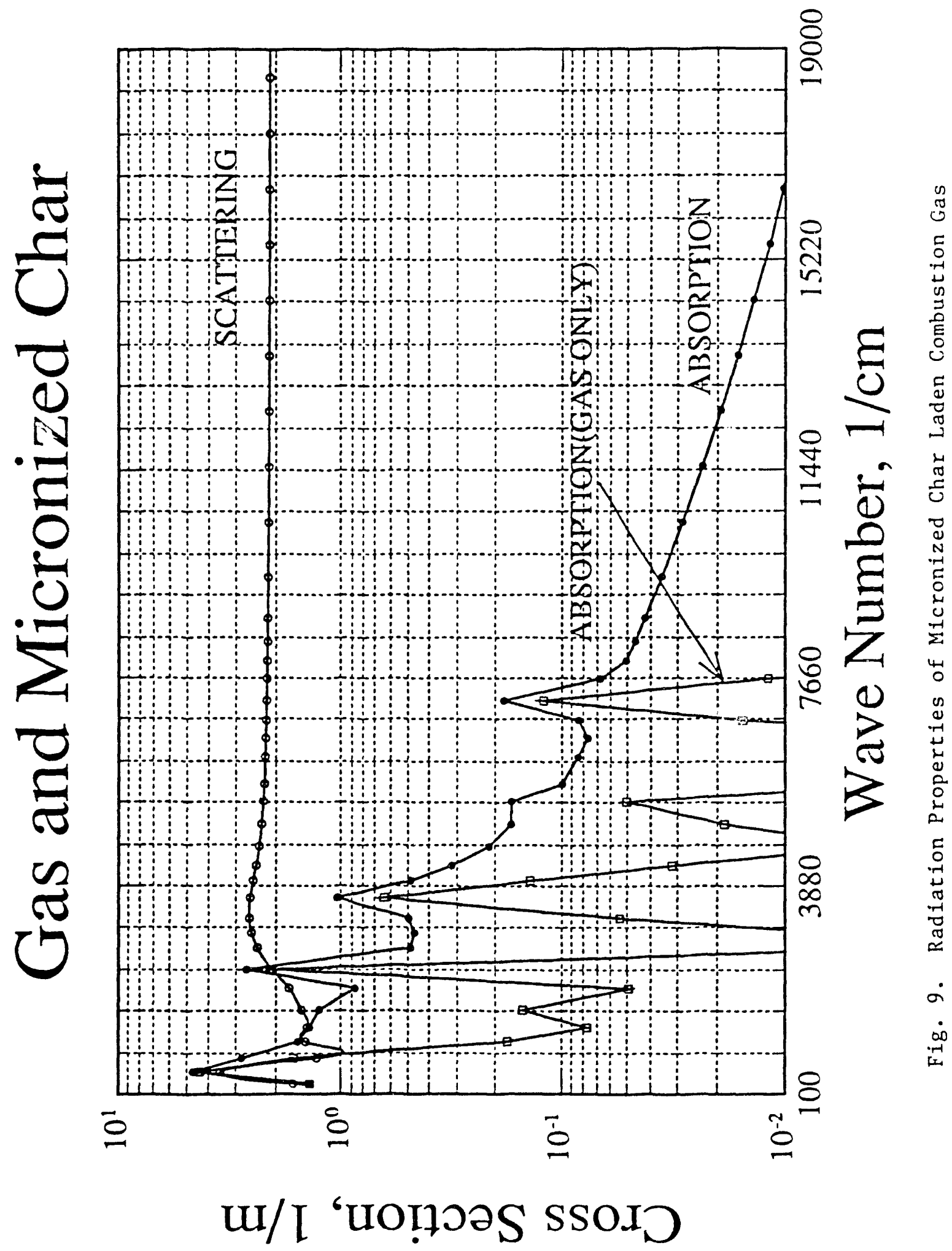


gas bands vanish, and the absorption cross-section becomes finite at large wave numbers where no gas bands are present. The changes in absorption crosssection are most significant away from the band centers. The char particles are also effective scatterers of thermal radiation. The scattering albedo is essentially larger than 0.5 at all frequencies, exceeding 0.9 for wavenumbers greater than $7500 \mathrm{~cm}^{-1}$.

Figure 10 attempts to assess the role of soot particles in radiation transport. Even in small quantities, soot can potentially dominate the transport process. The major uncertainty lies in our ability to specify the production and destruction of soot particles. The importance of soot can be negated by its short lifetime. Because of its small size, the interaction of soot with thermal radiation generally falls in the Rayleigh scattering regime, in which case the absorption cross-section can be shown to be approximately proportional to the soot volume fraction. In this limit, soot psd does not affect radiative heat transfer, and scattering by soot particles is negligibly small. The sweeping conclusion, however, is tempered by the tendency of soot to form chain-like agglomerates in which case the size and shape of agglomerates can influence radiation transport.

Figure 11 displays the contribution of a high iron/low silica coal ash to radiation properties. With pulverized coal ash, the low-frequency structure of the gas bands remains intact; the windows between the low-frequency bands disappear, and the absorption coefficient becomes finite at high frequencies outside the range of gas bands. Also, scattering comes into play in a manner that suggests reduction of spectral heat transfer in the vicinity of lowfrequency gas band centers but enhancement in the wings and windows of the gas bands and at high frequencies. A significant change in radiation properties is observed as the parent coal is cleaned to reduce the ash content. Within the frequency range of gas vibrational and rotational bands, the absorption coefficient reverts to the band structure typical of gas radiation. Because of the ash particles, the absorption coefficient remains finite at high frequencies, and the radiation transport is dominated by scattering for wavenumbers larger than $4000 \mathrm{~cm}^{-1}$. 


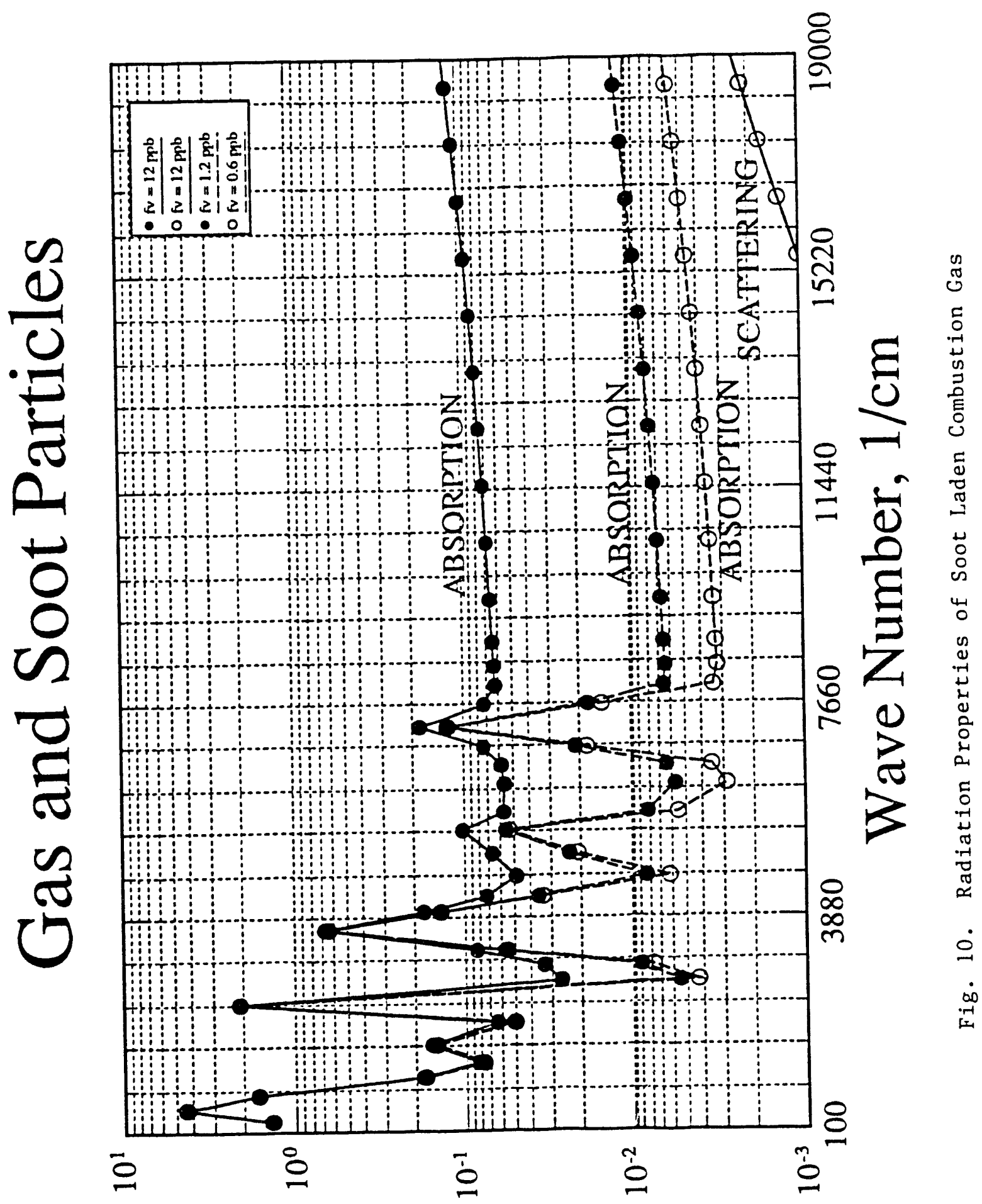

\section{u// 'UO!̣OวS SSOID}




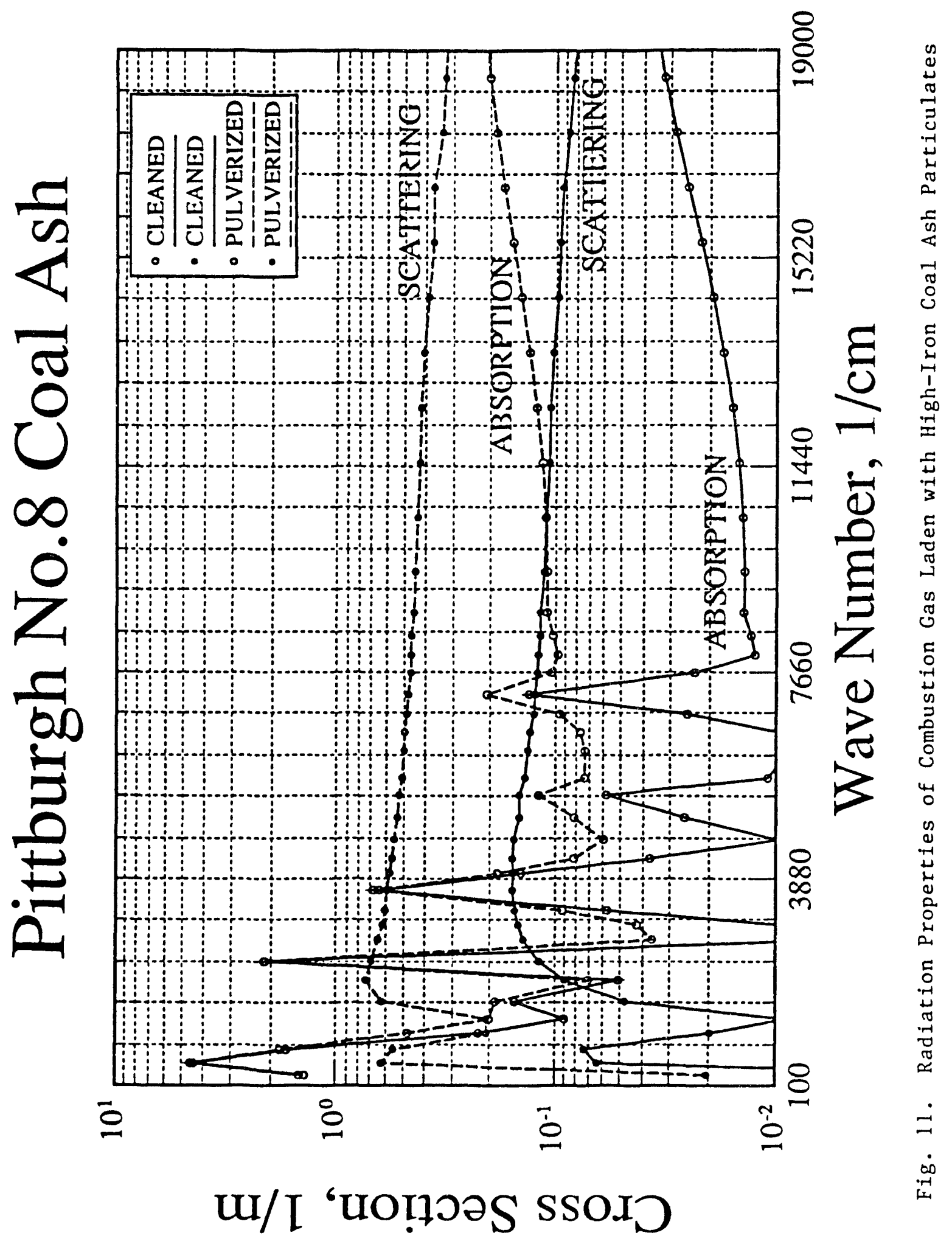


The effect of mineral matter composition on radiation cross-sections can be ascertained from results presented in Figs. 12 and 13. The Eastern coal type ash, low iron/high silica content, should be regarded as a scattering-type ash. The absorption coefficient of the combustion gas laden with Eastern type of ash reflects the overlapping band structure resulting from the simultaneous presence of $\mathrm{CO}_{2}$ and $\mathrm{H}_{2} \mathrm{O}$. Furthermore, the band structure is nearly independent of the ash content although the scattering coefficient decreases as the ash content is reduced. Thus, the effect of Eastern coal ash is purely to interject scattering into radiation transport. One would expect the radiative heat transfer to decrease because of the presence of Eastern coal ash. It also follows that heat transfer should improve (via reduction in scattering albedo) with cleaning of Eastern coal.

The Illinois No. 6 coal ash, characterized as a medium iron/medium silica ash, shows an intermediate character. With pulverized coal ash, the gas band structure is still visible although the windows between the bands have disappeared, and significant absorption at high frequencies is expected. As the ash content is reduced to $1 \%$, the gas band structure reemerges except that the scattering cross-section is significant in magnitude. With this type of ash, one might expect to have an enhancement in heat transfer when ash is present in concentration typical of pulverized coal, but reduction in heat transfer as the ash content is reduced to $1 \%$.

\section{DISCUSSION AND CONCLUSIONS}

Besides gaseous species, char and flyash are two main contributors to infrared radiation transport in coal-fired furnaces. The potential for enhancement in heat transfer by coal and soot particles is limited by the small lifetimes characterizing their transit through the fire-box region.

Within a coal furnace, the distribution and concentration of gaseous species and particulate matter are quite nonuniform. The hydrogen content of coal is converted to water vapor in a relatively short time as the volatile matter completes combustion. Over a longer time span, fixed carbon is oxi 


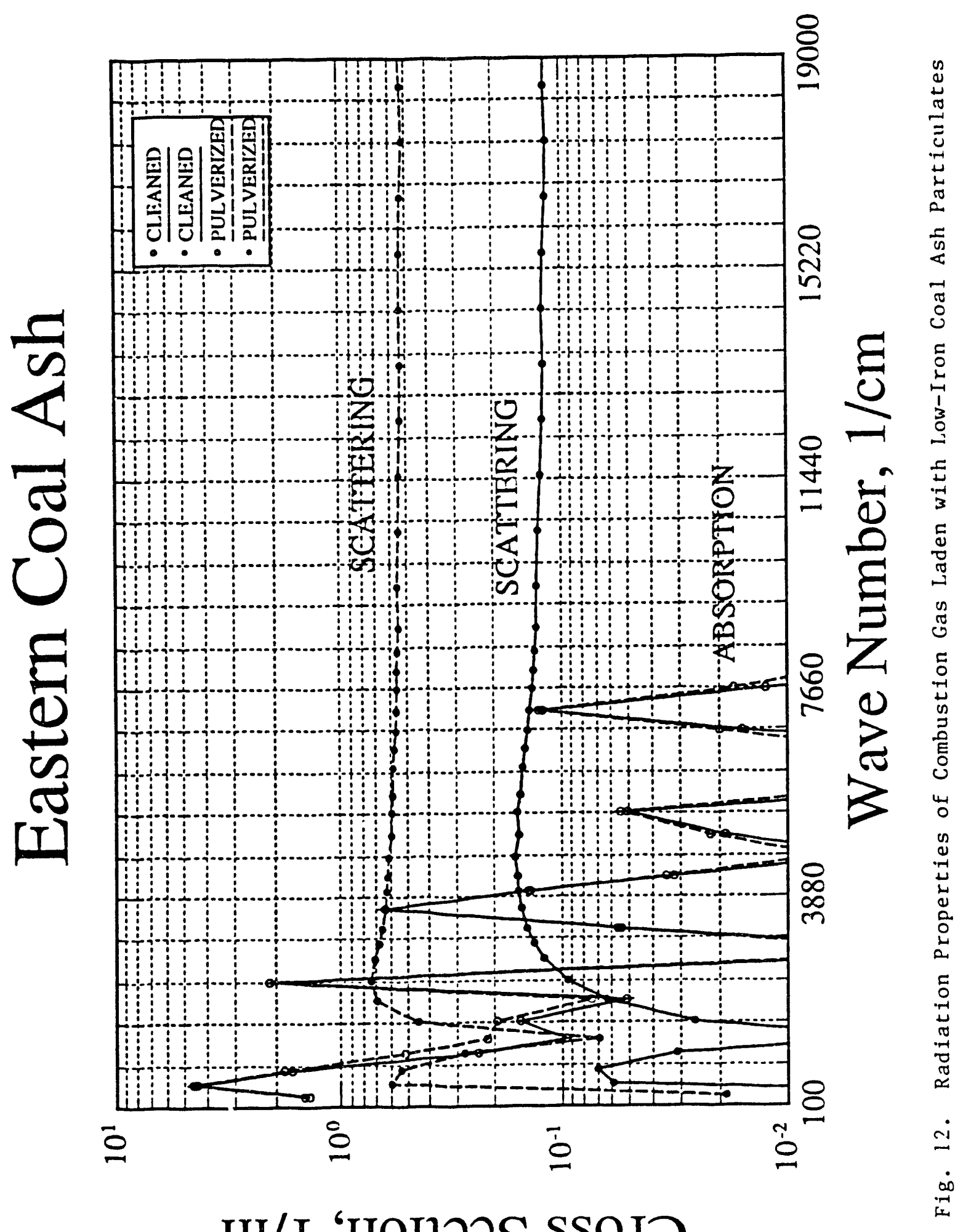




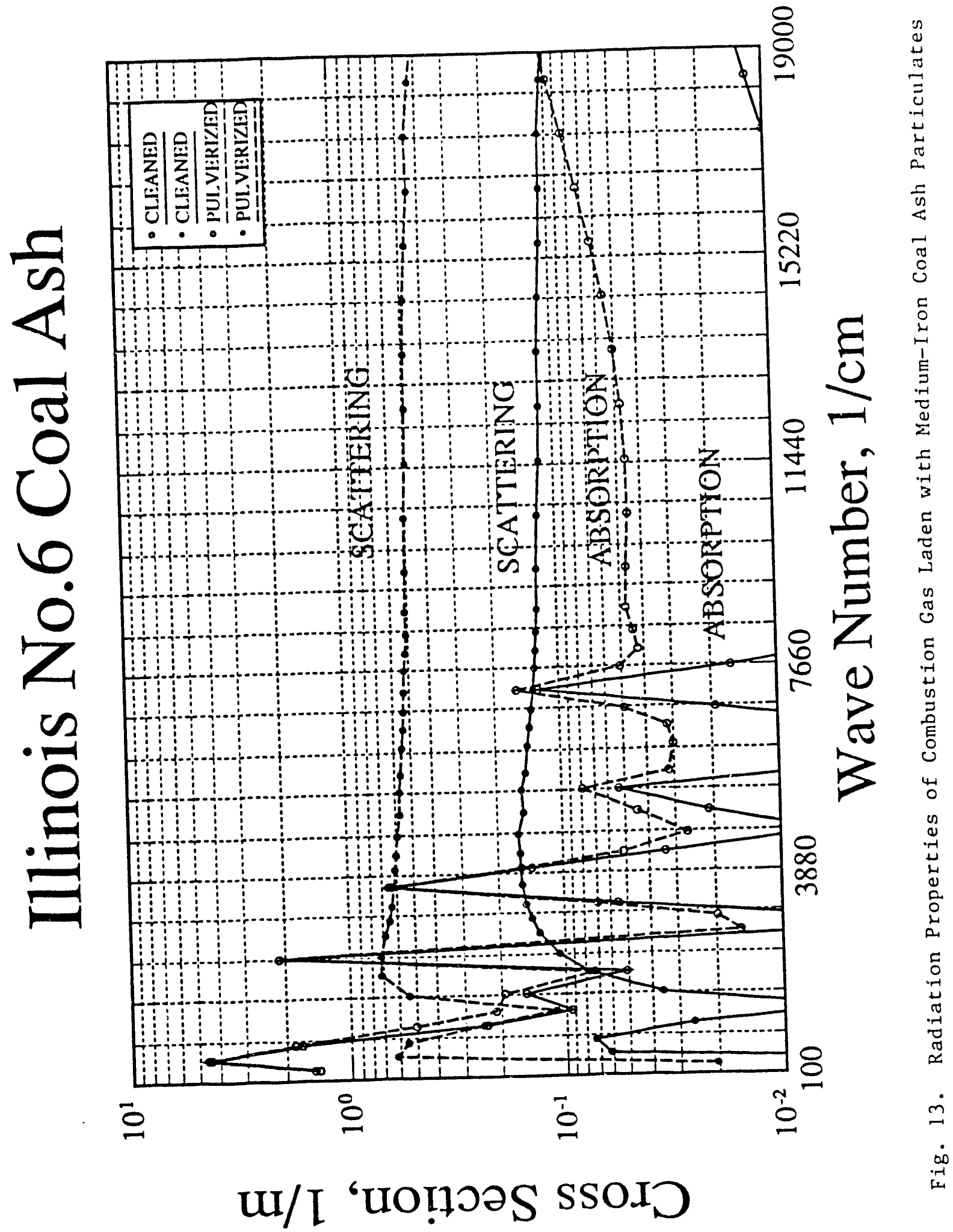


dized to carbon dioxide during char burnout. Flyash is liberated from the char matrix as the carbonaceous matter is gasified. Thus, one can identify two distinct furnace regions: a high temperature fire-box region with variable gas composition and particulate composition approximating the carbonaceous content of coal, and a heat absorption region with fixed combustion gas composition and particulate composition reflecting the mineral content of coal. Depending on the location and number of burners used in a furnace and the burner tilt angle, the flyash can occupy a greater portion of the furnace volume and be a more dominant contributor to radiative heat transfer than the char particles.

The radiative properties of molecular combustion products have been studied extensively. Empirical wide-band and narrow-band models have been formulated for estimating the spectral emissivity and absorptivity of combustion gases. Rigorous heat transfer models, based on solution of the radiation transport equation in multidimensional geometries, require a knowledge of absorption coefficient $\left(x_{v}\right)$. An apparent absorption coefficient can be estimated from the gas emissivity. It has an undesirable property of being mean beam length dependent even though $x_{v}$ is theoretically a point property.

There is a general paucity of experimental data on optical constants of char. We have conducted a dispersion analysis of the transmissivity measurements by Brewster and Kunitomo (1984) on char particles dispersed in infrared transmissive $\mathrm{KBr}$ pellets. There is some question on the uniqueness of the optical constants inferred purely from the extinction measurement. The necessity of measuring a second independent variable has been recognized in order to resolve properly the contributions of absorption and scattering to extinction efficiency. There is also some concern regarding extrapolating data to wavelengths smaller than $2.5 \mu \mathrm{m}$ since the disagreement between the dispersion correlation and the experimental data was largest at short wavelengths. The short wavelength region is important in radiative heat transfer since, at typical furnace temperatures, the peak in blackbody emissive power tends to be in the region $\lambda<2.5 \mu \mathrm{m}$. Finally, no attempt has been made to explain the optical behavior of char in terms of the known absorption bands of graphite even though char shares many structural similarities with graphite. 
Although an extensive data base exists on the optical constants of ash, its usefulness is compromised by the attendant experimental uncertainties or the analytical techniques employed for data reduction. Most comprehensive measurements in a controlled laboratory setting have been conduct/d by Goodwin [1986], and we recommend correlations based on his experimental data. One particularly useful aspect of his data is the attempt to explain and correlate ash optical constants in terms of the composition of the mineral matter and the known ausorption bands of the constituent oxides. Thus, the correlations are potentially useful for estimating the optical constants of any coal ash. We have observed that the correlation estimates absorption index consistently lower than the experimental measurements of other investigators. The correlation dces not account for the unburnt carbon content in flyash. Measurements by Gupta and Wall [1985] indicate enhancement in absorption index by residual carbon. In utility furnaces, one would expect the flyash to contain some (10\% or less) unburnt carbon since complete combustion of fixed carbon is not always attainable. Thus, an extension of Goodwin correlation to account for residual carbon content would be most desirable.

We have performed several parametric calculations to elucidate the role of suspended particulates in determining the radiation properties of coal flames. One effect of combustion particulates is to modify the band structure of gas radiation by absorbing infrared radiation in the windows of $\mathrm{CO}_{2}$ and $\mathrm{H}_{2} \mathrm{O}$ bands and in the high frequency region where no gas bands are present. The char and ash particles are also effective scatterers of thermal radiation. The scattering albedo of gas-char and gas-ash mixtures is essentially larger than 0.5 at all frequencies, exceeding 0.9 in the near-visible region. The role of ash particles is determined by the mineral composition, in particular the iron content. Flyash may be classified as absorbing type or scattering type depending on whether it is high or low in iron content.

The parametric calculations point to a significant impact of coal beneficiation and micronization on radiation properties and heat transfer. The flyash contribution to furnace heat transfer is expected to decrease with coal cleaning if the parent coal ash is rich in fron or if iron is selectively removed in the cleaning process. Conversely, if the parent coal ash is low in iron content, heat transfer should improve with reduction in ash content. 


\section{REFERENCES}

Blokh, A. G., 1988, Heat Transfer in Steam Boiler Furnaces, Hemisphere Publishing Corporation.

Bohren, C. F. and Huffman, D. R., 1983, Absorption and Scattering of Light by Small Particles, John Wiley \& Sons, Inc.

Brewster, M. Q. and Kunitomo, T., 1984, "The Optical Constants of Coal. Char, and Limestone," Journal of Heat Transfer, Vol. 106, pp. 678-683.

Clough, S. A., Kneizys, F. X., and Chetwynd, J. H., 1977, "Algorithm for Calculation of Absorption Coefficient-Pressure Broadened Molecular Transitions," AFGL-TR-77-0164.

Edwards, D. K., 1976, "Molecular Gas Band Radiation," Advances in Heat Transfer, Vol. 12, pp. 115-193.

Foster, P. J. and Howarth, C. R., 1968, "Optical Constants of Carbons and Coals in the Infrared," Carbon, Vol. 6, pp. 719-729.

Goodwin, D. G., 1986, "Infrared Optical Constants of Coal Slags," HTGL Report No. T-255, Stanford, CA.

Grosshandler, W. L. and Monteiro, S. L. P., 1982, "Attenuation of Thermal Radiation by Pulverized Coal and Char," Journal of Heat Transfer, Vol. 104, pp. 587-593.

Gupta, R. P. and Wall, T. F., 1985, "The Optical Properties of Fly Ash in Coal Fired Furnaces," Combustion and Flame, Vol. 61, pp. 145-151.

Hauser, J. J., 1977, "Electrical, Structural and Optical Properties of Amorphour Carbon," Journal of Non-Crystalline Solids, Vol. 23, pp. 21-41.

Lee, S. C. and Tien, C. L., 1981, "Optical Constants of Soot in Hydrocarbon Flames, "Eighteenth Symposium (International) on Combustion, The Combustion Institute, PP. 1159-1166.

Lowe, A., Stewart, I. M. and Wall, T. F., 1979, "The Measurement and Interpretation of Radiation from Fly Ash Particles in Large Pulverized Coal Flames," Seventeenth Symposium (International) on Combustion, The Combustion Institute, pp. 105-114.

Ludwig, C. B. et al., 1973, Handbook of Infrared Radiation from Combustion Gases, NASA SP-3080.

Rothman, L. S. et al., 1987, "The HITRAN Database: 1986 edition," Applied Optics, Vol. 26, No. 19, pp. 4058-4097.

Solomon, P. R. et al., 1986, "The Spectral Emittance of Pulverized Coal and Char," Twenty-first symposium (International) on Combustion, The Combustion Institute, pp. 437-446. 
Toon, O. B. and Pollack, J. B., 1976, "The Optical Constants of Several Atmospheric Aerosol Species: Ammonium Sulfate, Aluminum Oxide, and Sodium Chloride," Journal of Geophysical Research, Vol. 81, No. 33, pp. 5733-5748.

Volz, F. E., 1973, "Infrared Optical Constants of Ammonium Sulfate, Sahara Dust, Volcanic Pumice, and Flyash," Applied Optics, Vol. 12, pp. 564-568.

Willis, C., 1970, "The Complex Refractive Index of Particles in a Flame," Journal of Physics D: Applied Physics, Vo1. 3, pp. 1944-1956.

Wyatt, P. J., 1980, "Some Chemical, Physical, and Optical Properties of Fly Ash Particles," Applied Optics, Vol. 19, No. 6, pp. 975-983. 


\section{Distribution for ANL/FE-91/2}

Internal:
R. Ahluwal ia (10)
K. Leong
C. Till
S. Bhattacharyya
L. LeSage
D. Wade
H. Drucker
v. Novick
TIS Files (3)
K. Im (10)
H. Park
I. Lee
D. Schmalzer
ANL Contract File
ANL Patent Dept.

\section{External:}

DOE-OSTI, for distribution per UC-104 (49)

ANL Libraries

DOE Chicago Operations Office:
Manager
D. Bray
F. Herbaty

U.S. Department of Energy. Washington:
W. Fedarko
C. Garrett

DOE Morgantown Energy Technology Center:
Director
N. Holcombe
J. Byam
J. Notestein
J. Strickland
L. Carpenter
T. O'Brien
H. Webb

DOE Pittsburgh Energy Technology Center:

$\begin{array}{lll}\text { Director } & \text { J. Hickerson } & \text { L. Ruth } \\ \text { R. Carrabetta } & \text { S. Kim } & \text { J. Winslow } \\ \text { P. Goldberg } & \text { M. Mathur } & \end{array}$

Other Government-University-Industry:

M. Brewster, University of Illinois, Urbana, IL

P. Chung, University of Illinois, Chicago, IL

D. Goodwin, California Institute of Technology, Pasadena, CA

R. Piccireili, Wayne State University, Detroit, MI

M. Ramezan, Burns \& Roe Services Corporation, Pittsburgh, PA 

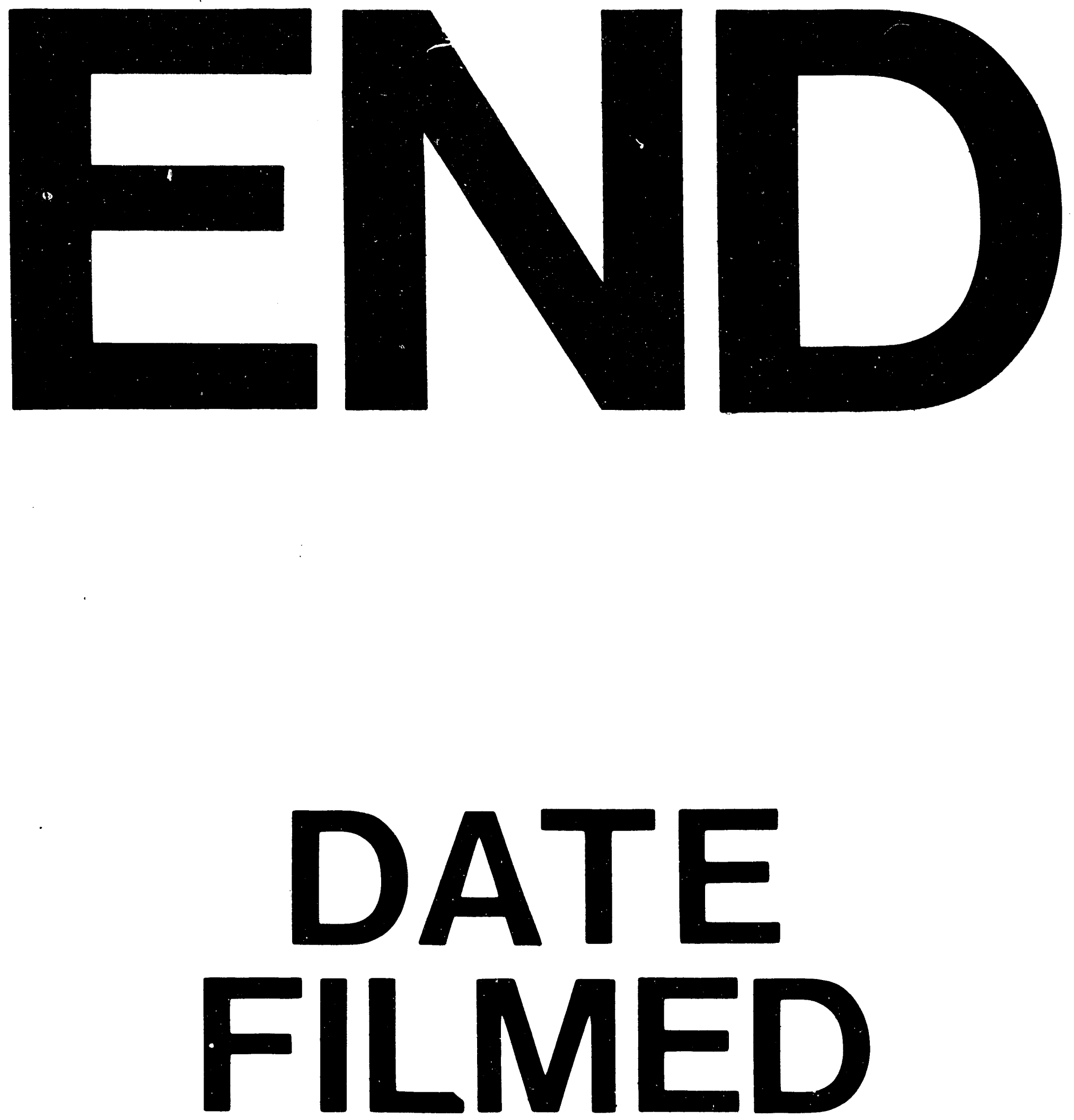

1

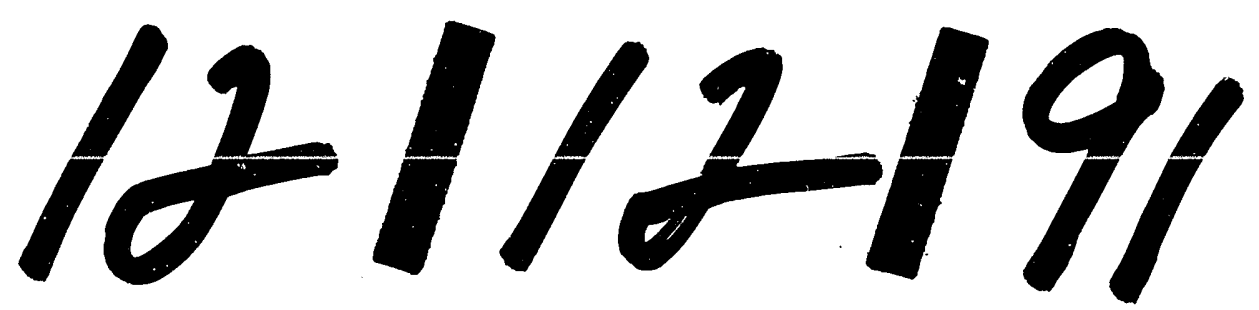

" 
